\title{
Effect of breast-conserving surgery plus radiotherapy versus mastectomy on breast cancer-specific survival for early-stage contralateral breast cancer
}

\author{
Chao Qian ${ }^{1 \#}$, Yan Liang ${ }^{2 \#}$, Min Yang ${ }^{3 \#}$, Sheng-Nan Bao ${ }^{2}$, Jian-Ling Bai ${ }^{3}$, Yong-Mei Yin ${ }^{2}$, Hao Yu ${ }^{3}$ \\ ${ }^{1}$ Department of General Surgery, Sir Run Run Hospital, Nanjing Medical University, Nanjing, China; ${ }^{2}$ Department of Oncology, The First Affiliated \\ Hospital of Nanjing Medical University, Nanjing, China; ${ }^{3}$ Department of Biostatistics, School of Public Health, Nanjing Medical University, \\ Nanjing, China \\ Contributions: (I) Conception and design: C Qian, Y Liang, M Yang; (II) Administrative support: H Yu, YM Yin, JL Bai; (III) Provision of study \\ materials or patients: C Qian; (IV) Collection and assembly of data: C Qian, Y Liang; (V) Data analysis and interpretation: C Qian, M Yang, SN Bao; \\ (VI) Manuscript writing: All authors; (VII) Final approval of manuscript: All authors. \\ "These authors contributed equally to this work. \\ Correspondence to: Hao Yu. Department of Biostatistics, School of Public Health, Nanjing Medical University, 101 Longmian Avenue, Nanjing \\ 211166, China. Email: haoyu@njmu.edu.cn; Yong-Mei Yin. Department of Oncology, The First Affiliated Hospital of Nanjing Medical University, \\ 300 Guangzhou Road, Nanjing 210029, China. Email: ymyin@njmu.edu.cn; Jian-Ling Bai. Department of Biostatistics, School of Public Health, \\ Nanjing Medical University, 101 Longmian Avenue, Nanjing 211166, China. Email: jbai@njmu.edu.cn.
}

Background: Breast-conserving surgery followed by radiotherapy is recommended in most women with early-stage unilateral breast cancer. However, its role in contralateral breast cancer (CBC) patients remains unclear. This retrospective study aimed to evaluate the breast cancer-specific survival (BCSS) outcomes after breast-conserving surgery plus radiotherapy compared with mastectomy in women with early-stage (T12N0-1M0) CBC.

Methods: Data were extracted from the Surveillance, Epidemiology, and End Results database. BCSS was analyzed using the log-rank method, competing risks regression model, and propensity score matching method.

Results: A total of 9,336 early-stage CBC patients were included. After multivariable adjustment, no significant difference in BCSS was found between early-stage CBC patients undergoing breast-conserving surgery plus radiotherapy and those undergoing mastectomy [hazard ratio (HR) 1.11, 95\% confidence interval (CI): 0.90-1.37, $\mathrm{P}=0.329]$. BCSS was similar in both treatment groups and in the subgroups stratified by age at first primary breast cancer or $\mathrm{CBC}$ diagnosis $(\leq 50,51-60$, and $>60$ years), time interval between cancers $(<0.25,0.25-4,5-9$, and $\leq 10$ years), stage of first primary breast cancer, $\mathrm{T}$ classification of CBC, histology and hormone receptors status of both cancers (all P>0.05). Among patients with N1 disease at CBC diagnosis, breast-conserving surgery plus radiotherapy was associated with a boundary significantly improved BCSS (HR 1.45, 95\% CI: 1.00-2.12, P=0.050). Among patients who underwent breast-conserving surgery for first primary cancer, bilateral mastectomy for contralateral cancer did not improve BCSS compared with breast-conserving surgery plus radiotherapy $(\mathrm{P}>0.05)$. There was no significant difference in BCSS between breast-conserving surgery plus radiotherapy and mastectomy plus radiotherapy $(\mathrm{P}>0.05)$. Stable results were obtained after propensity score matching.

Conclusions: Breast-conserving surgery plus radiotherapy did not significantly influence BCSS outcomes of patients with early-stage CBC. Bilateral mastectomy and mastectomy plus radiotherapy did not confer a survival advantage over breast-conserving surgery plus radiotherapy in these patients. Future prospective studies are necessary to expand on these results.

^ ORCID: 0000-0002-5869-9227. 
Keywords: Breast-conserving surgery (BCS); mastectomy; contralateral breast cancer (CBS); survival

Submitted Jun 21, 2021. Accepted for publication Sep 02, 2021.

doi: 10.21037 /gs-21-413

View this article at: https://dx.doi.org/10.21037/gs-21-413

\section{Introduction}

A growing number of women are living with a history of breast cancer due to increased incidence and reduced mortality. For example, in the United States, the breast cancer-associated death rate has dropped by $40 \%$ since 1989 (1) and it is estimated that more than 3.8 million women have a history of invasive breast cancer (2). Approximately $0.5 \%$ of these breast cancer survivors will develop contralateral breast cancer (CBC) every year (3). With the growing number of breast cancer survivors, the number of women with CBC is dramatically increasing, from $2.6 \%$ in 1975 to $7.5 \%$ in 2014 among all breast cancers in the United States (4). Thus, CBC has become an increasingly important public health problem.

Breast-conserving surgery (BCS) followed by radiotherapy is associated with fewer post-surgical complications and better cosmetic effects as compared with mastectomy. It has been recommended in most women with early-stage unilateral breast cancer (UBC) since 1990 (5). This recommendation was based on findings from several randomized controlled trials, showing similar survival outcomes between early-stage UBC patients treated with BCS plus radiotherapy and those treated with mastectomy (6-9). However, the role of BCS in treating CBC patients remains unclear. As a clinical trial in this context is not feasible, populationbased observational studies may provide relevant insights. This retrospective study used data from the Surveillance, Epidemiology, and End Results (SEER) database to evaluate the breast cancer-specific survival (BCSS) outcomes after BCS plus radiotherapy compared with mastectomy in women with early-stage CBC. In this study, early-stage CBC is defined as T1-2N0-1M0 (tumor size $\leq 5 \mathrm{~cm}$ and $0-3$ ipsilateral axillary lymph nodes metastases), who could be offered either BCS or mastectomy. We present the following article in accordance with the STROBE reporting checklist (available at https://dx.doi.org/10.21037/gs-21-413).

\section{Methods}

\section{Database}

This retrospective study was based on 18 SEER cancer registries (released in April 2019, based on the November 2018 submission) and used the SEER*Stat software (http:// www.seer.cancer.gov/seerstat; version 8.3.6). The current SEER database includes approximately $30 \%$ of the United States population; hence, it is considered nationally representative. As the SEER data are de-identified and publicly available, this study was exempted from the informed consent or institutional review board approval requirements. The study was conducted in accordance with the Declaration of Helsinki (as revised in 2013).

\section{Study population}

Patients with multiple primary breast cancer whose first primary breast cancer (FPBC) diagnosed between 1998 and 2010 were eligible for this study if they met the following criteria: (I) T1-2N0-1M0 CBC with non-metastatic FPBC; (II) treated with $\mathrm{BCS}$ or mastectomy either at the time of FPBC or CBC diagnosis; (III) aged 18-80 years either at the time of $\mathrm{FPBC}$ or $\mathrm{CBC}$ diagnosis.

Patients were excluded if they had other malignancies, ipsilateral secondary breast cancer or unknown cancer laterality, lacked histologic diagnostic confirmation or had missing information on tumor-node-metastasis (TNM) staging of $\mathrm{FPBC}$ or $\mathrm{CBC}$. We excluded women with stage IV FPBC to minimize the misclassification of metastatic disease as primary disease. Patients undergoing bilateral mastectomy for FPBC were also excluded because in this case contralateral primary disease and recurrence disease were difficult to distinguish. As radiotherapy is a standard post-BCS component, patients undergoing BCS for CBC with none/unknown radiotherapy were also excluded. A total of 9,336 early-stage (T1-2N0-1M0) CBC patients were included in our study (the flow diagram of the 


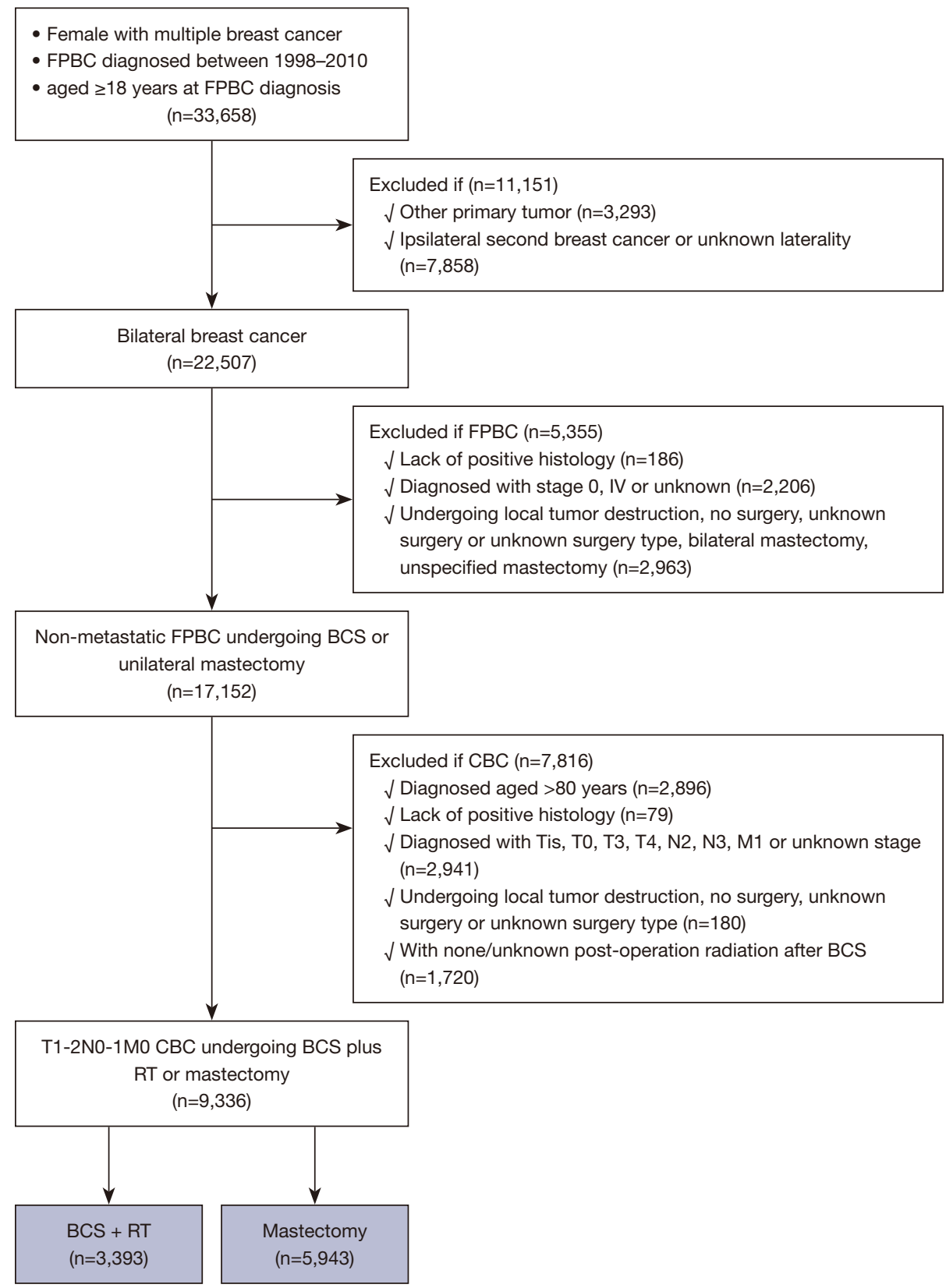

Figure 1 Flow diagram of the inclusion and exclusion criteria. SEER, Surveillance, Epidemiology, and End Results; FPBC, first primary breast cancer; CBC, contralateral breast cancer; BCS, breast-conserving surgery; RT, radiotherapy.

inclusion and exclusion criteria is presented in Figure 1).

\section{Variables of interest}

Treatment-related characteristics accounted for included type of surgery and information of radiation. Surgery for CBC was categorized as BCS [RX Summ-Surg Prim Site (1998+) codes 21-24] with radiotherapy or mastectomy [unilateral mastectomy codes: 41, 43-46, 51, 53-56, 61, 64-67, and 71; bilateral mastectomy codes: 42, 47-49, 52, $57-59,62,63,68,69,72-75$; mastectomy (unilateral or bilateral is not otherwise specified) code: $30,40,50,60$, 70, 80] with or without radiotherapy.

Patient demographic characteristics included race (White, Black, others, and unknown), normalized cost-ofliving index of state of residence $(\leq 1,000$ and $>1,000)$, age at 
FPBC or CBC diagnosis ( $\leq 50,51-60$, and $>60$ years), and the time interval between cancers $(<0.25,0.25-4,5-9$, and $\geq 10$ years). Tumor characteristics included breast-adjusted 6th edition American Joint Committee on Cancer (AJCC 6th) stage of FPBC [stage I (T1N0M0), stage II (T4N0M0, T2-3N0M1, T1-2N1M0), and stage III (T3-4N1M0, T1-4N2-3M0)], AJCC 6th T classification of CBC [T1 (tumor size $\leq 2 \mathrm{~cm}$ ) and $\mathrm{T} 2$ (tumor size $>2 \mathrm{~cm}$ but $\leq 5 \mathrm{~cm}$ )], AJCC 6th N classification of CBC [N0 (no lymph node metastasis) and N1 (1-3 lymph node metastases)], and grade [Grade I (well differentiated), Grade II (moderately differentiated), Grade III (poorly differentiated) or Grade IV (undifferentiated), and unknown], histology [infiltrating ductal carcinoma (IDC), infiltrating lobular carcinoma (ILC) ILC mixed with other types, and others], estrogen receptor (ER) status (positive, negative or borderline, and unknown) and progesterone receptor (PR) status (positive, negative or borderline, and unknown) of both cancers.

\section{Statistical analysis}

BCSS was assessed. It was defined as the time from CBC diagnosis until death due to breast cancer or last follow-up. The follow-up cut-off date was 31 December, 2017.

Baseline characteristics were compared between the treatment groups using Fisher's exact probability test for nominal categorical variables and the rank-sum test for ordinal categorical variables or continuous variables. BCSS rates were calculated using the log-rank test. Univariable and multivariable analyses were performed to identify factors associated with BCSS. Considering potential competing risks (death due to non-breast cancer causes), hazard ratios (HRs) for BCSS were assessed using Fine and Gray's competing risks regression model (10). Subgroup analyses were used to validate the independent association. Among patients who underwent BCS for FPBC, we separately compared survival outcomes in three groups according to surgery types for CBC: BCS plus radiotherapy, unilateral mastectomy, and bilateral mastectomy (patients were excluded if the type of mastectomy was not specified). As information regarding radiotherapy in the current SEER database is classified as "yes" or "none/unknown", mastectomy with radiotherapy and mastectomy without radiotherapy are not directly comparable (11). Thus, to further investigate whether mastectomy plus radiotherapy could confer a survival benefit over BCS plus radiotherapy in early-stage CBC patients, BCSS was separately estimated and compared between BCS plus radiotherapy and mastectomy plus radiotherapy. Given that women undergoing mastectomy might represent higher-risk populations, we performed propensity score (PS) matching at a $1: 1$ or $1: 4$ ratio with a caliper of 0.2 to reduce the associated imbalance.

All statistical analyses were performed using SAS version 9.4 (SAS Institute Inc) and R version 4.0.2 (The R Foundation for Statistical Computing). Statistical significance was set at $\mathrm{P}$ values $<0.05$.

\section{Results}

A total of 9,336 early-stage (T1-2N0-1M0) CBC patients were included in this study and divided into the BCS plus radiotherapy $(\mathrm{n}=3,393)$ and mastectomy (with or without radiotherapy; $\mathrm{n}=5,943$ ) groups (Table 1 ). The median followup time was 81 months (range, $0-227$ months).

\section{Baseline characteristics between BCS plus radiotherapy and mastectomy in early-stage CBC patients}

The baseline characteristics of all patients are presented in Table 1. Women aged $\leq 50$ years at CBC diagnosis ( $21.78 \%$ vs. $33.55 \%)$ were less likely to undergo BCS plus radiotherapy compared with mastectomy. The median age at CBC diagnosis in patients undergoing BCS plus radiotherapy and mastectomy was 64 (IQR, 56-72) and 60 (IQR, 51-69) years, respectively. A higher proportion of patients undergoing mastectomy had synchronous contralateral breast cancer (SCBC, time interval between FPBC and $C B C<0.25$ years) compared with those undergoing BCS plus radiotherapy (29.68\% vs. 37.59\%). Patients in the BCS plus radiotherapy group were more likely to have stage I FPBC (63.93\% vs. $44.09 \%)$, T1 (86.91\% vs. $76.56 \%$ ) or N0 (N0, 87.18\% vs. $79.12 \%$ ) CBC compared with those in the mastectomy group. Patients with grade III/IV tumor (FPBC: Grade III/IV, 34.34\% vs. 26.47\%. CBC: Grade III/IV, $28.47 \%$ vs. $23.19 \%)$, negative/ borderline hormone receptor (FPBC: ER negative/ borderline, $21.96 \%$ vs. $17.45 \%$; PR negative/borderline, $29.80 \%$ vs. $26.05 \%$. CBC: ER negative/borderline, $20.33 \%$ vs. $15.27 \%$; PR negative/borderline, $32.91 \%$ vs. $28.06 \%$ ), ILC or mixed ILC histology (FPBC: ILC, 9.19\% vs. 6.81; mixed ILC, $12.89 \%$ vs. $9.52 \%$. CBC: ILC, $11.48 \%$ vs. $9.02 \%$; mixed ILC, $12.33 \%$ vs. $10.79 \%$ ), either in FPBC or $\mathrm{CBC}$, were more likely to undergo mastectomy rather than BCS plus radiotherapy. In the BCS plus radiotherapy group, the majority (91.10\%) underwent BCS for FPBC; 
Table 1 Baseline characteristics between BCS plus RT and mastectomy in early-stage CBC patients

\begin{tabular}{|c|c|c|c|c|}
\hline Characteristic & $\mathrm{BCS}+\mathrm{RT}(\mathrm{n}=3,393), \mathrm{n}(\%)$ & Mastectomy (n=5,943), n (\%) & Total $(n=9,336), n(\%)$ & $P$ value \\
\hline \multicolumn{5}{|c|}{ Demographic-associated characteristic } \\
\hline Race & & & & 0.008 \\
\hline Black & $332(9.78)$ & $567(9.24)$ & $899(9.63)$ & \\
\hline Others & $264(7.78)$ & $549(9.24)$ & $813(8.71)$ & \\
\hline CoL index of state of residence & & & & 0.300 \\
\hline$\leq 1,000$ & $1,294(38.14)$ & $2,332(39.24)$ & $3,626(38.84)$ & \\
\hline$>1,000$ & $2,099(61.86)$ & $3,611(60.76)$ & $5,710(61.16)$ & \\
\hline Age at FPBC diagnosis(years) & & & & $<0.000$ \\
\hline Age at CBC diagnosis (years) & & & & $<0.000$ \\
\hline$\leq 50$ & $413(12.17)$ & $1,378(23.19)$ & $1,791(19.18)$ & \\
\hline $51-60$ & $837(24.67)$ & $1,618(27.23)$ & $2,455(26.30)$ & \\
\hline$>60$ & $2,143(63.16)$ & $2,947(49.59)$ & $5,090(54.52)$ & \\
\hline Time interval (years) & & & & $<0.000$ \\
\hline$<0.25$ & $1,007(29.68)$ & $2,234(37.59)$ & $3,241(34.72)$ & \\
\hline $0.25-4$ & 985 (29.03) & $2,637(28.25)$ & 2,637 (28.25) & \\
\hline $5-9$ & $913(26.91)$ & $2,300(24.64)$ & $2,300(24.64)$ & \\
\hline III/IV & $898(26.47)$ & $2,041(34.34)$ & 2,939 (31.48) & \\
\hline Unknown & $154(4.54)$ & $353(5.94)$ & $507(5.43)$ & \\
\hline Histology of FPBC & & & & $<0.000$ \\
\hline IDC & 2,479 (73.06) & $4,006(67.41)$ & $6,485(69.46)$ & \\
\hline ILC & $231(6.81)$ & $546(9.19)$ & 777 (8.32) & \\
\hline Mixed ILC & $323(9.52$ & 766 (12.89) & $1,089(11.66)$ & \\
\hline Others & $360(10.61)$ & 625 (10.52) & 985 (10.55) & \\
\hline Stage of FPBC & & & & $<0.000$ \\
\hline Stage I & 2,169 (63.93) & $2,620(44.09)$ & $4,789(51.30)$ & \\
\hline Stage II & $1,025(30.21)$ & $2,451(41.24)$ & $3,476(37.23)$ & \\
\hline Stage III & $199(5.87)$ & $872(14.67)$ & $1,071(11.47)$ & \\
\hline
\end{tabular}

Table 1 (continued) 
Table 1 (continued)

\begin{tabular}{|c|c|c|c|c|}
\hline Characteristic & $\mathrm{BCS}+\mathrm{RT}(\mathrm{n}=3,393), \mathrm{n}(\%)$ & Mastectomy ( $\mathrm{n}=5,943), \mathrm{n}(\%)$ & Total $(n=9,336), n(\%)$ & $P$ value \\
\hline Positive & $2,541(74.89)$ & $4,155(69.91)$ & $6,696(71.72)$ & \\
\hline Negative or Borderline & $592(17.45)$ & $1,305(21.96)$ & $1,897(20.32)$ & \\
\hline Unknown & $260(7.66)$ & $483(8.13)$ & $743(7.96)$ & \\
\hline PR status of FPBC & & & & $<0.000$ \\
\hline Negative or Borderline & $884(26.05)$ & $1,771(29.80)$ & $2,655(28.44)$ & \\
\hline Unknown & $299(8.81)$ & $571(9.32)$ & $870(9.32)$ & \\
\hline Surgery type for FPBC & & & & $<0.000$ \\
\hline BCS & $3,091(91.10)$ & $1,676(28.20)$ & $4,767(51.06)$ & \\
\hline Grade of CBC & & & & $<0.000$ \\
\hline I & $1,044(30.77)$ & $1,481(24.92)$ & $2,525(27.05)$ & \\
\hline II & $1,407(41.47)$ & $2,403(40.43)$ & $3,810(40.81)$ & \\
\hline III/IV & $787(23.19)$ & $1,692(28.47)$ & $2,479(26.55)$ & \\
\hline Unknown & $155(4.57)$ & $367(6.18)$ & $522(5.59)$ & \\
\hline Histology of CBC & & & & $<0.001$ \\
\hline IDC & $2,475(72.94)$ & $4,075(68.57)$ & $6,550(70.16)$ & \\
\hline ILC & $306(9.02)$ & $682(11.48)$ & $988(10.58)$ & \\
\hline Mixed ILC & $366(10.79)$ & $733(12.33)$ & $1,099(11.77)$ & \\
\hline NO & 2,958 (87.18) & $4,702(79.12)$ & $7,660(82.05)$ & \\
\hline N1 & $435(12.82)$ & $1,241(20.88)$ & $1,676(17.95)$ & \\
\hline ER status of $C B C$ & & & & $<0.000$ \\
\hline Positive & 2,714 (79.99) & $4,239(71.33)$ & $6,953(74.48)$ & \\
\hline Negative or borderline & $518(15.27)$ & $1,208(20.33)$ & $1,726(18.49)$ & \\
\hline Unknown & $161(4.75)$ & $496(8.35)$ & $657(7.04)$ & \\
\hline PR status of CBC & & & & $<0.000$ \\
\hline Positive & $2,259(66.58)$ & $3,428(57.68)$ & $5,687(60.91)$ & \\
\hline Negative or borderline & $952(28.06)$ & 1,956 (32.91) & 2,908 (31.15) & \\
\hline Unknown & $182(5.36)$ & $559(9.41)$ & $741(7.94)$ & \\
\hline
\end{tabular}

Data are shown as number (percentage). FPBC, first primary breast cancer; CBC, contralateral breast cancer; BCS, breast-conserving surgery; RT, radiotherapy; CoL, cost-of-living; IDC, infiltrating ductal carcinoma; ILC, infiltrating lobular carcinoma; ER, estrogen receptor; $\mathrm{PR}$, progesterone receptor. 


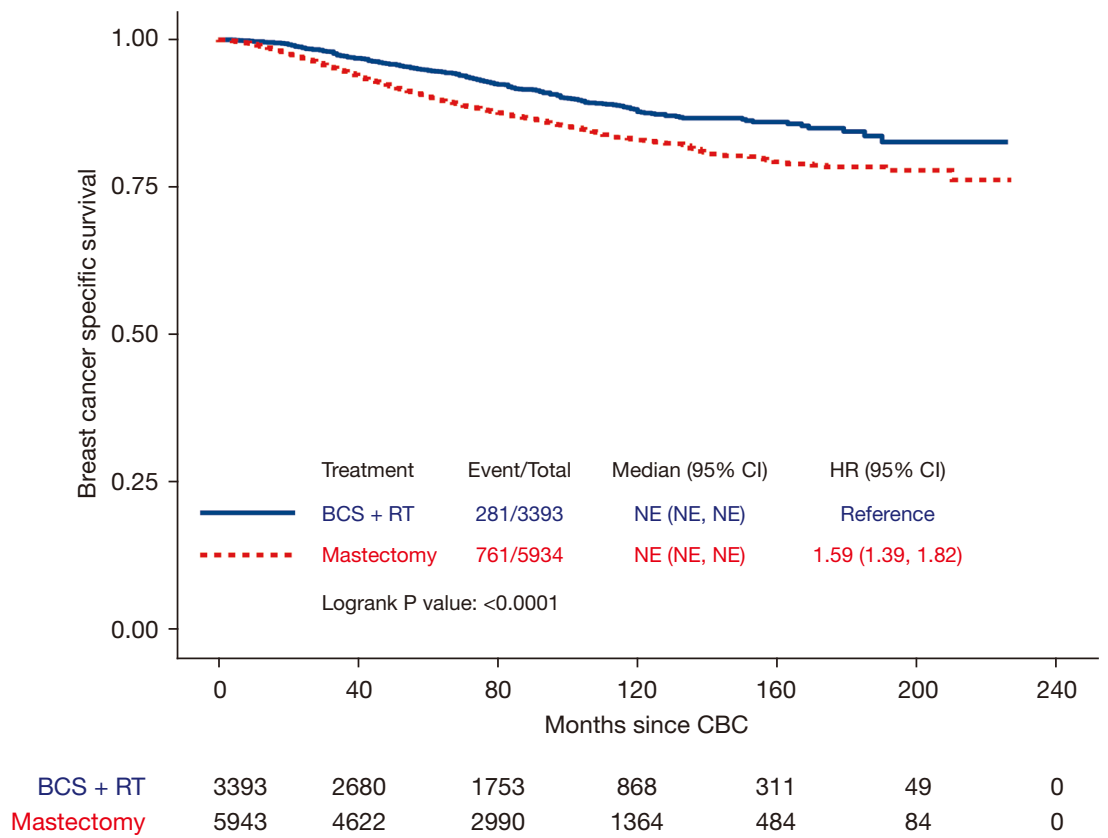

Figure 2 Kaplan-Meier curves of BCSS as compared between BCS plus RT and mastectomy treatments in early-stage CBC patients. BCSS, breast cancer-specific survival; CBC, contralateral breast cancer; BCS, breast-conserving therapy; RT, radiotherapy; HR, hazard ratio; CI, confidence interval.

in the mastectomy group, most patients $(71.80 \%)$ received mastectomy for FPBC; more patients went from BCS for FPBC to mastectomy for CBC than patients went from mastectomy for FPBC to BCS for CBC (28.20\% vs. 8.90\%).

\section{BCSS of patients with early-stage CBC}

The 10-year BCSS rate among CBC patients was $87.81 \%$ and $83.00 \%$ in the BCS plus radiotherapy and the mastectomy groups, respectively. Log-rank tests indicated that early-stage CBC patients undergoing BCS plus radiotherapy had better BCSS compared with those undergoing mastectomy (log-rank $\mathrm{P}<0.000)$ (Figure 2).

In univariable analyses (Table S1), race, age at CBC diagnosis, time interval between two cancers, grade of FPBC, histology of FPBC, stage of FPBC, ER status of FPBC, PR status of FPBC, surgery type for FPBC, grade of CBC, T classification of CBC, $\mathrm{N}$ classification, ER status of $\mathrm{CBC}$, and $\mathrm{PR}$ status of $\mathrm{CBC}$ were significantly associated with BCSS (all $\mathrm{P}<0.05$ ). BCS plus radiotherapy was significantly associated with better BCSS as compared with mastectomy [HR 1.59, 95\% confidence interval (CI): $1.39-1.82, \mathrm{P}<0.000]$.

In the multivariable models (Table 2), race and cost- of-living index of state of residence did not impact BCSS $(\mathrm{P}>0.05)$. Aged $>60$ years at $\mathrm{CBC}$ diagnosis was associated with poorer BCSS compared with aged $\leq 50$ years (HR 1.24, 95\% CI: $1.02-1.50, \mathrm{P}=0.027)$. The time interval between FPBC and CBC was an independent predictor of BCSS. Compared with the time interval of $<0.25$ years, worse BCSS was associated with the time interval of $0.25-4$ years (HR 1.41, 95\% CI: 1.18-1.70, $\mathrm{P}<0.001$ ), similar BCSS was associated with that of $5-9$ years $(\mathrm{P}>0.05)$, and better BCSS was associated with that of $\geq 10$ years (HR $0.57,95 \%$ CI: 0.38-0.87, $\mathrm{P}=0.009)$. Characteristics of FPBC that were associated with BCSS included tumor grade (Grade II vs. Grade I: HR 1.35, 95\% CI: 1.07-1.70, P=0.012; Grade III/ IV vs. Grade I: HR 1.39, 95\% CI: 1.06-1.80, $\mathrm{P}=0.015)$ and stage (stage II vs. stage I: HR 2.05, 95\% CI: 1.71-2.46, $\mathrm{P}<0.000$; stage III vs. stage I: HR 5.21, 95\% CI: 4.20-6.48, $\mathrm{P}<0.000)$. Histology, ER status, PR status, and surgery type of FPBC were not significantly associated with BCSS $(\mathrm{P}>0.05)$. Characteristics of $\mathrm{CBC}$ that were associated with BCSS included tumor grade (Grade II vs. Grade I: HR 1.54, 95\% CI: 1.24-1.89, P<0.000; Grade III/IV vs. Grade I: HR 1.58, 95\% CI $1.24-2.03,95 \%$ CI: $1.34-1.88, \mathrm{P}<0.001$ ), T classification (T2 vs. T1: HR 1.59, 95\% CI: $1.34-1.88$, $\mathrm{P}<0.000$ ), $\mathrm{N}$ classification (N1 vs. N0: HR 1.78, 95\% CI: 
Table 2 Multivariable analysis for BCSS in early-stage CBC patients

\begin{tabular}{lll}
\hline \multirow{2}{*}{ Characteristic } & \multicolumn{2}{c}{ BCSS } \\
\cline { 2 - 3 } & HR $(95 \% \mathrm{Cl}) \quad$ P value \\
\hline
\end{tabular}

Demographic-associated characteristic

Race

White

Black

Reference

Others

$1.04(0.82-1.33)$

0.718

$0.90(0.68-1.19)$

0.467

CoL index of state of residence

$$
\begin{aligned}
& \leq 1,000 \\
& >1,000
\end{aligned}
$$

Reference

$1.01(0.87-1.17)$

0.919

Age at $\mathrm{CBC}$ diagnosis (years)

$\leq 50$

$51-60$

$>60$

Time interval (years)

$\begin{array}{lcc}<0.25 & \text { Reference } & \\ 0.25-4 & 1.41(1.18-1.70) & <0.001 \\ 5-9 & 0.96(0.76-1.21) & 0.737 \\ \geq 10 & 0.57(0.38-0.87) & 0.009\end{array}$

FPBC-associated characteristic

Grade of FPBC

I

II

III/IV

$\begin{array}{cc}\text { Reference } & \\ 1.07(0.87-1.31) & 0.548 \\ 1.24(1.02-1.50) & 0.027\end{array}$

$1.24(1.02-1.50) \quad 0.027$

Histology of FPBC

IDC

ILC

Mixed ILC

Others

Stage of FPBC

Stage I

Stage II

Stage III

ER status of FPBC

Positive

Reference

Negative/Borderline

Table 2 (continued)

$1.17(0.91-1.50) \quad 0.226$

Reference
Table 2 (continued)

\begin{tabular}{lcc}
\hline \multirow{2}{*}{ Characteristic } & \multicolumn{2}{c}{ BCSS } \\
\cline { 2 - 3 } & HR $(95 \%$ Cl) & P value \\
\hline PR status of FPBC & Reference \\
Positive & $0.96(0.76-1.21)$ & 0.751 \\
Negative/Borderline & & \\
Surgery type for FPBC & Reference \\
BCS & $0.85(0.70-1.04)$ & 0.123 \\
Mastectomy &
\end{tabular}

CBC-associated characteristic

Grade of CBC

I

II

III/IV

$1.53(1.24-1.89)<0.000$

$1.58(1.24-2.03) \quad<0.001$

Histology of CBC

IDC

Reference

ILC

Mixed ILC

$0.96(0.73-1.27) \quad 0.797$

Others

$0.95(0.75-1.20) \quad 0.660$

$1.10(0.82-1.49) \quad 0.525$

T classification of $\mathrm{CBC}$

T1

Reference

T2

$1.58(1.34-1.88) \quad<0.000$

$\mathrm{N}$ classification of $\mathrm{CBC}$

NO

Reference

N1

$1.78(1.52-2.10) \quad<0.000$

ER status of CBC

Positive

Reference

Negative/Borderline

$1.15(0.89-1.48) \quad 0.286$

PR status of $\mathrm{CBC}$

Positive

Negative/Borderline

Reference

Surgery type for CBC

$\mathrm{BCS}+\mathrm{RT}$

Mastectomy

$1.11(0.90-1.37) \quad 0.329$

BCSS, breast cancer-specific survival; HR, hazard ratio; $\mathrm{Cl}$, confidence interval; FPBC, first primary breast cancer; $\mathrm{CBC}$, contralateral breast cancer; CoL, cost-of-living; IDC, infiltrating ductal carcinoma; ILC, infiltrating lobular carcinoma; ER, estrogen receptor; PR, progesterone receptor; BCS, breast-conserving surgery; RT, radiotherapy. 
1.52-2.10, $\mathrm{P}<0.000$ ), and $\mathrm{PR}$ status (negative/borderline $v s$. positive: HR 1.28, 95\% CI: 1.04-1.57, $\mathrm{P}=0.022)$. Histology and ER status of CBC had no impact on BCSS $(\mathrm{P}>0.05)$. Notably, women undergoing BCS plus radiotherapy for CBC had similar BCSS (HR 1.11, 95\% CI: 0.90-1.37, $\mathrm{P}=0.329$ ) as compared with those undergoing mastectomy.

After 1:1 PS matching, 1,449 CBC patients who underwent BCS plus radiotherapy were matched with 1,449 patients who underwent mastectomy (Table S2). Overall imbalance between the two surgical treatment groups improved substantially with standardized mean differences less than 0.1 for all variables (Table S2 and Figure S1). Similar to the result from the pre-matched cohort, no difference was found between the treatment groups after multivariable adjustment in the post-matched cohort (HR 1.02, 95\% CI: 0.81-1.30, P=0.846) (result not shown in table and figure).

\section{Subgroup analysis}

First, we performed subgroup analysis with patients stratified by age at FPBC and $\mathrm{CBC}$ diagnosis, the time interval between cancers, stage of FPBC, $\mathrm{T}$ and $\mathrm{N}$ classification of $\mathrm{CBC}$, histology and hormone receptors status of both cancers (Figure 3).

There were no significant differences between BCS plus radiotherapy and mastectomy in any of the subgroups defined by age at FPBC diagnosis $(\leq 50,51-60,>60$ years) (all $\mathrm{P}>0.05)$ or by age at CBC diagnosis $(\leq 50,51-60$, $>60$ years) (all $\mathrm{P}>0.05$ ) (Figure 3). BCSS was similar in both treatment groups among patients with SCBC $(\mathrm{P}>0.05)$. Similar SCBC-associated findings were observed in patients with metachronous contralateral breast cancer (MCBC) at time intervals of $0.25-4$ years, 4-9 years, and $\geq 10$ years (all $\mathrm{P}>0.05$ ). In the subgroups stratified by FPBC stage (stage I, stage II, and stage III) or CBC T classification (T1 or T2), BCSS was not affected by surgery type used for CBC $(\mathrm{P}>0.05)$. Among patients with N0 disease at CBC diagnosis, no significant difference in BCSS was found in both treatment groups $(\mathrm{P}>0.05)$; in the $\mathrm{N} 1$ subgroup, BCS plus radiotherapy was associated with a boundary significantly improved BCSS compared with mastectomy (HR 1.45, 95\% CI: 1.00-2.12, P=0.050). Furthermore, BCSS was similar in both treatment groups even when divided into subgroups stratified by histology (IDC, ILC, mixed ILC, and others) of the two cancers, and ER or PR status (positive, negative or borderline) of the two cancers (all $\mathrm{P}>0.05$ ).
Next, we performed subgroup analysis stratified by surgery types for FPBC (Figure 4).

Among patients who underwent mastectomy for FPBC, there was no significant difference in BCSS between BCS plus radiotherapy and mastectomy for CBC after multivariable adjustment $(\mathrm{P}>0.05)$ (Figure 4).

Among patients who underwent BCS for FPBC, we separately compared BCSS outcomes in three groups according to surgery types for CBC: BCS plus radiotherapy $(\mathrm{n}=3,091)$, unilateral mastectomy $(\mathrm{n}=1,676)$, and bilateral mastectomy $(\mathrm{n}=728)$ (Table 3). Patients undergoing mastectomy but the type was not specified $(n=170)$ were excluded. We noticed that the characteristics such as cost-ofliving index of state of residence, time interval, FPBC grade, FPBC histology, FPBC stage, and CBC grade were balanced (all $\mathrm{P}>0.05$ ) between the unilateral and bilateral mastectomy groups. White $(84.07 \%$ vs. $76.86 \%)$ and younger patients ( $\leq 60$ years at CBC diagnosis, $60.44 \%$ vs. $42.16 \%$ ) were more likely to undergo bilateral mastectomy rather than unilateral mastectomy. And patients with negative or borderline hormone receptor (FPBC: ER negative/borderline, 32.28\% vs. $25.58 \%$; PR negative/ borderline, $39.29 \%$ vs. $32.39 \%$. CBC: ER negative/borderline, $31.87 \%$ vs. $25.84 \%$; PR negative/borderline, $43.68 \%$ vs. 39.72\%), either in FPBC or CBC, were more likely to receive bilateral mastectomy than unilateral mastectomy. However, patients in the unilateral mastectomy group were more likely to have T2 $(29.05 \%$ vs. $24.04 \%)$ or N1 (24.94\% vs. $19.01 \%)$ CBC compared with those in the bilateral mastectomy group. After multivariable adjustment (Figure 4), neither unilateral mastectomy nor bilateral mastectomy improved BCSS as compared with BCS plus radiotherapy among patients who had BCS for FPBC (both $\mathrm{P}>0.05$ ).

\section{BCS plus radiotherapy and mastectomy plus radiotherapy for early-stage CBC patients}

In the mastectomy group, $520(8.75 \%)$ patients were recorded to receive radiotherapy (Table 4). These patients were much more likely to be aged $\leq 50$ years at CBC diagnosis (30.19\% vs. 12.17\%), and have stage II/III FPBC (stage II, $43.85 \%$ vs. $30.21 \%$; stage III, $25.19 \%$ vs. 5.87 ) and T2 (42.17\% vs. $13.09 \%)$ or N1 (54.81\% vs. $12.82 \%)$ CBC compared with those underwent BCS plus radiotherapy. After multivariable adjustment (Figure 5), no significant difference was found in BCSS between the BCS plus radiotherapy and mastectomy plus radiotherapy groups (HR 1.16, 95\% CI: $0.80-1.69, \mathrm{P}=0.429)$. We further stratified 


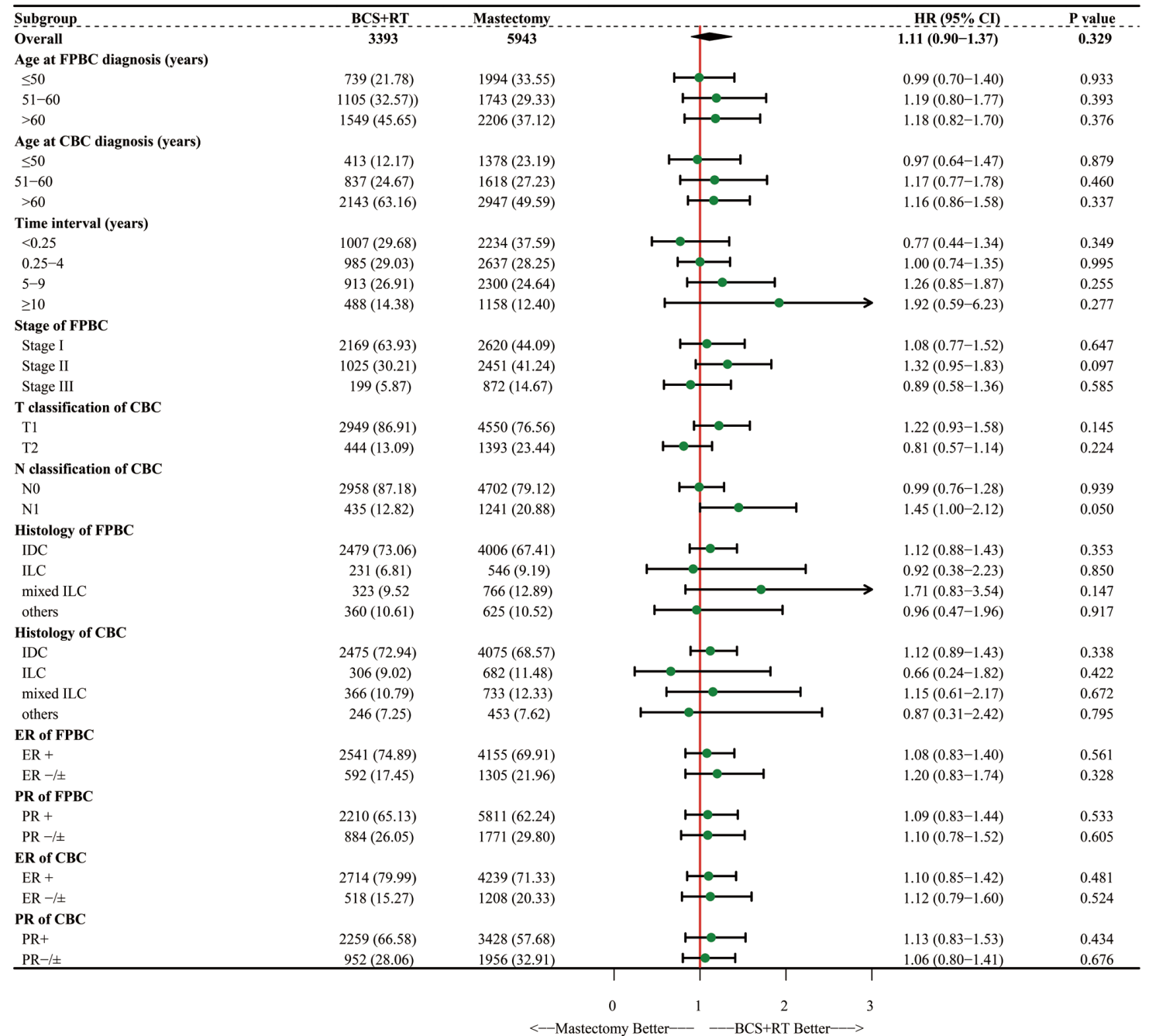

Figure 3 Multivariable analysis for BCSS stratified by age at FPBC and CBC diagnosis, the time interval between cancers, stage of FPBC, $\mathrm{T}$ and $\mathrm{N}$ classification of CBC, histology and hormone receptors status of both cancers. BCSS, breast cancer-specific survival; HR, hazard ratio; CI, confidence interval; FPBC, first primary breast cancer; CBC, contralateral breast cancer; BCS, breast-conserving surgery; RT, radiotherapy; IDC, infiltrating ductal carcinoma; ILC, infiltrating lobular carcinoma; ER, estrogen receptor; PR, progesterone receptor.

these patients according to the $\mathrm{N}$ classification of CBC. BCSS was comparable between BCS plus radiotherapy and mastectomy with radiotherapy either in the N0 subgroup (HR 0.90, 95\% CI: 0.54-1.49, $\mathrm{P}=0.689$ ) or N1 subgroup (HR 1.65, 95\% CI: 0.97-2.81, $\mathrm{P}=0.060$ ).

After 1:4 PS matching, 890 patients remained eligible for further multivariable analysis, including 712 and 178 patients in the BCS plus radiotherapy and mastectomy plus radiotherapy groups, respectively (Table S3). Apart from PR status of CBC, overall imbalance between the two surgical treatment groups improved substantially with standardized mean differences less than 0.1 (Table S3 and
Figure S2). Likewise, stable results were obtained from the post-matched cohort (Figure S3). No significant differences were found in BCSS between BCS plus radiotherapy and mastectomy plus radiotherapy in the matched whole cohorts and the subgroups stratified by $\mathrm{N}$ classification (N0 and N1) of CBC (all $\mathrm{P}>0.05)$.

\section{Discussion}

Whether BCS plus radiotherapy is appropriate for patients with $\mathrm{CBC}$ remains unclear. As $\mathrm{CBC}$ tends to be a new primary breast cancer (12), it is generally suggested that 


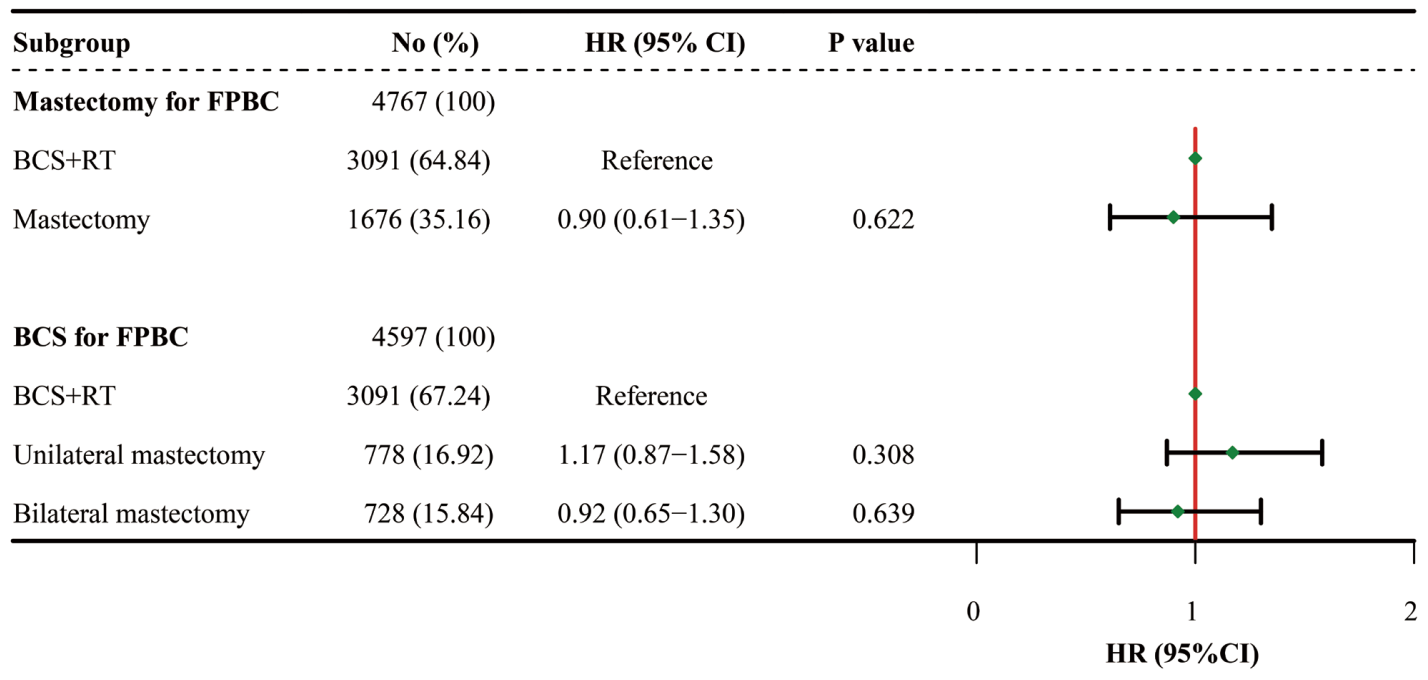

Figure 4 Multivariable analysis for BCSS stratified by surgery type for FPBC. Adjusted for age at CBC diagnosis, time interval, stage of FPBC, T and N classification of CBC, histology and hormone receptors status of both cancers. BCSS, breast cancer-specific survival; HR, hazard ratio; CI, confidence interval; FPBC, first primary breast cancer; CBC, contralateral breast cancer; BCS, breast-conserving therapy; RT, radiotherapy.

the treatment strategy for CBC resembles therapy for UBC. However, limited data are available to support this contention. Only a few retrospective studies have reported on this (13-18). Gollamudi et al. (14) found no significant differences in survival outcomes, cosmetic outcomes, or complication rates between CBC patients and UBC patients receiving BCS. The result was consistent with those of Fung et al. (13) and Lee et al. (15). Furthermore, de la Rochefordiere et al. (18) found that survival did not differ significantly when comparing SCBC patients undergoing bilateral BCS with those undergoing bilateral or unilateral mastectomy. Nevertheless, these single-center studies were all conducted on a small number of samples (1760 patients).

One of the strengths of this study was the large numbers of early-stage CBC patients, obtained from a representative population-wide database that included detailed demographic and clinical characteristics. In this study, we found that BCSS was comparable between early-stage CBC patients undergoing BCS plus radiotherapy and those undergoing mastectomy. The results may help patients and doctors in decision-making regarding surgery for CBC.

Enhanced surveillance after the FPBC diagnosis often results in early detection of $\mathrm{CBC}$. However, despite being eligible for BCS, most $\mathrm{CBC}$ patients are more likely to choose mastectomy over BCS $(4,19)$. Anxiety associated with the second breast cancer may motivate patients to pursue a more aggressive treatment strategy. Consistent with Adkisson et al. (20), we found the majority of patients who underwent mastectomy for FPBC would continue choosing mastectomy at CBC diagnosis. The decision may result from the consideration of body symmetry. It is also not surprising to note that bilateral mastectomy was performed in a subset of CBC patients who had undergone BCS for FPBC, since bilateral mastectomy has been used increasingly in UBC patients in the past two decades despite no survival benefit $(21,22)$. However, even with reconstruction, patients undergoing bilateral mastectomy were less satisfied with their body image than those undergoing BCS (23). Moreover, the long-term quality of life remained lower among patients who underwent bilateral mastectomy compared with patients who had one breast conserved, including poorer sexual health and greater body image distress $(23,24)$.

In our study, patients who underwent mastectomy for FPBC had no difference in BCSS whether they again chose mastectomy or chose to conserve the newly involved breast at $\mathrm{CBC}$ diagnosis. Similarly, for patients treated with BCS for FPBC, neither unilateral mastectomy nor bilateral mastectomy for CBC brought better survival benefits over bilateral BCS. In this case, conserving one breast or both breasts may be beneficial in improving the long-term quality of life of CBC patients.

$\mathrm{CBC}$ is one of the clinical characters associated with an 
Table 3 Baseline characteristics of BCS plus RT, unilateral mastectomy, and bilateral mastectomy groups in early-stage CBC patients who underwent BCS for FPBC

\begin{tabular}{|c|c|c|c|c|c|c|}
\hline Characteristic & $B C S+R T(n=3,091)$ & $\begin{array}{c}\text { Unilateral } \\
\text { mastectomy }(n=778)\end{array}$ & $\begin{array}{l}\text { Bilateral mastectomy } \\
\qquad(\mathrm{n}=728)\end{array}$ & Total $(n=4,597)$ & $P$ value $^{\dagger}$ & $P$ value \\
\hline \multicolumn{7}{|c|}{ Demographic-associated characteristic } \\
\hline White & 2,567 (83.05) & $598(76.86)$ & $612(84.07)$ & $3,777(82.16)$ & & \\
\hline Unknown & $2(0.06)$ & $0(0.00)$ & $2(0.07)$ & $3(0.07)$ & & \\
\hline \multicolumn{7}{|l|}{ CoL index of state of residence } \\
\hline$\leq 1,000$ & $1,195(38.66)$ & 308 (39.59) & $258(34.04)$ & $1,761(38.31)$ & 0.198 & 0.097 \\
\hline $51-60$ & $766(24.78)$ & $187(24.04)$ & $241(33.10)$ & $1,194(25.97)$ & & \\
\hline$>60$ & $1,950(63.09)$ & $450(57.84)$ & $288(39.56)$ & $2,688(58.47)$ & & \\
\hline Time interval (years) & & & & & $<0.000$ & 0.137 \\
\hline$<0.25$ & $954(30.86)$ & $55(7.07)$ & $11(1.51)$ & $1,020(22.19)$ & & \\
\hline $0.25-4$ & $893(28.89)$ & $297(38.17)$ & $293(40.25)$ & $1,483(32.26)$ & & \\
\hline $5-9$ & $814(26.33)$ & $276(35.48)$ & $296(40.66)$ & 1,386 (30.15) & & \\
\hline$\geq 10$ & $430(13.91)$ & $150(19.28)$ & $128(17.58)$ & 708 (15.40) & & \\
\hline Unknown & $141(4.56)$ & $51(6.56)$ & $34(4.67)$ & 226 (4.92) & & \\
\hline Histology of FPBC & & & & & 0.299 & 0.277 \\
\hline IDC & $2,272(73.50)$ & $563(72.37)$ & $549(75.41)$ & $3,384(73.61)$ & & \\
\hline ILC & $203(6.57)$ & $44(5.66)$ & $36(4.95)$ & $283(6.16)$ & & \\
\hline Mixed ILC & $286(9.25)$ & $82(10.54)$ & $57(7.83)$ & $425(9.25)$ & & \\
\hline Others & $330(10.68)$ & 89 (11.44) & $86(11.81)$ & 505 (10.99) & & \\
\hline Stage of FPBC & & & & & $<0.000$ & 0.061 \\
\hline Stage I & $2,062(66.71)$ & $472(60.67)$ & 405 (55.63) & 2,939 (63.93) & & \\
\hline Stage II & $899(29.08)$ & $261(33.55)$ & 279 (38.32) & $1,439(31.30)$ & & \\
\hline Stage III & $130(4.21)$ & $45(5.78)$ & $44(6.04)$ & $219(4.76)$ & & \\
\hline
\end{tabular}

Table 3 (continued) 
Table 3 (continued)

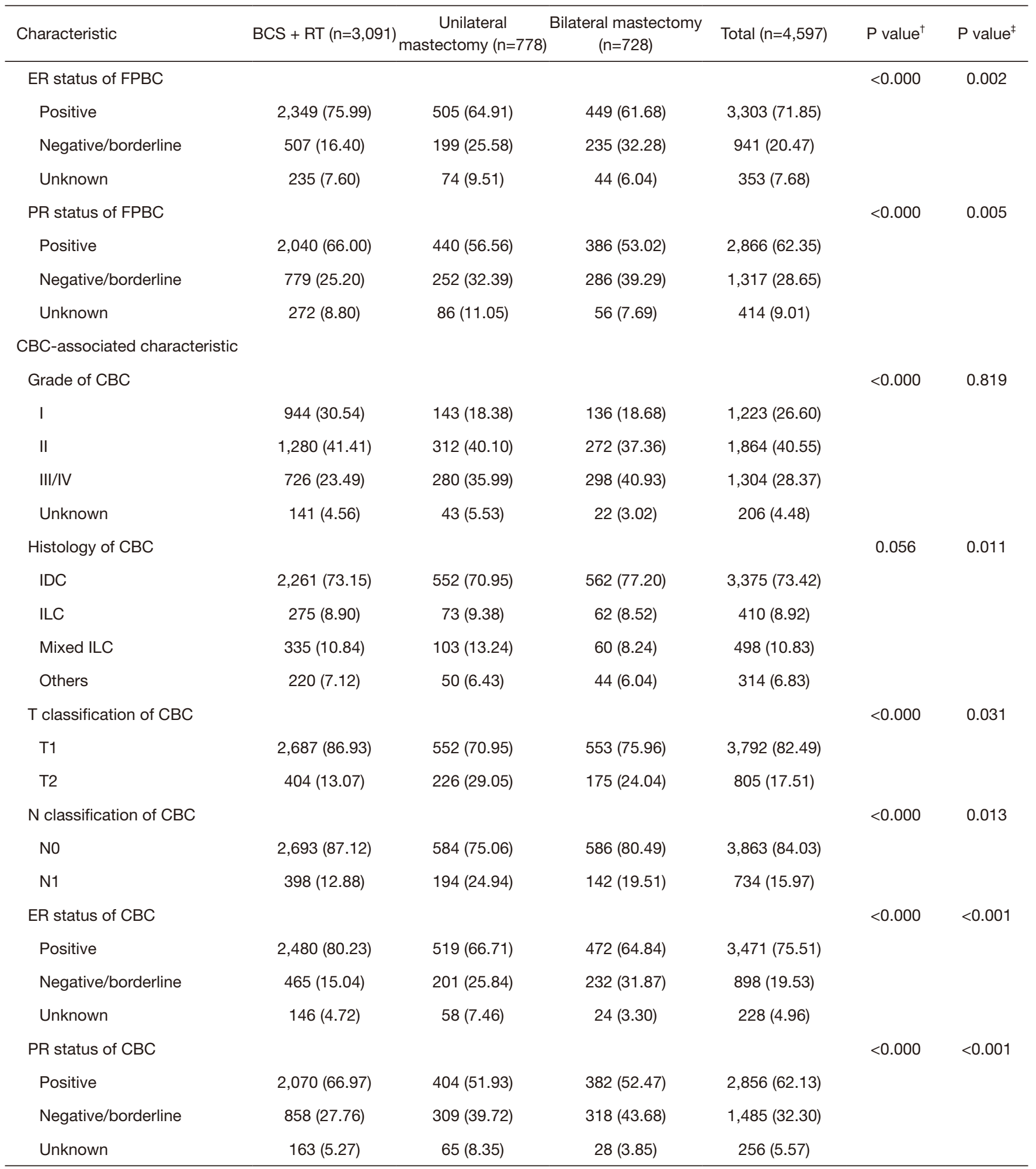

Data are shown as number (percentage). ${ }^{\dagger}, \mathrm{P}$ value between the three surgery types. ${ }^{\ddagger}, \mathrm{P}$ value between unilateral mastectomy and bilateral mastectomy. FPBC, first primary breast cancer; CBC, contralateral breast cancer; BCS, breast-conserving surgery; RT, radiotherapy; CoL, cost-of-living; IDC, infiltrating ductal carcinoma; ILC, infiltrating lobular carcinoma; ER, estrogen receptor; PR, progesterone receptor. 
Table 4 Baseline characteristics between BCS plus RT and mastectomy plus RT in early-stage CBC patients

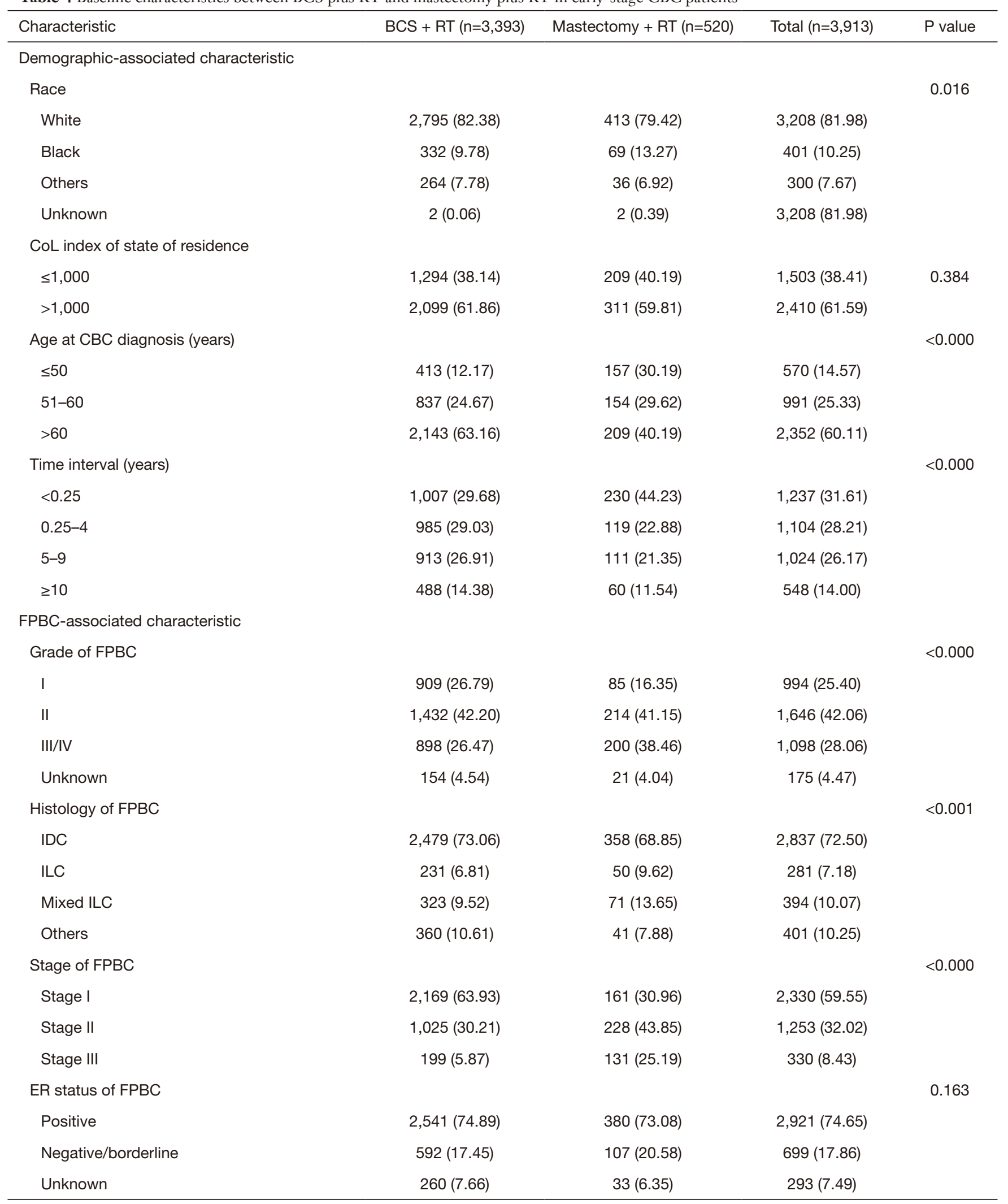

Table 4 (continued) 
Table 4 (continued)

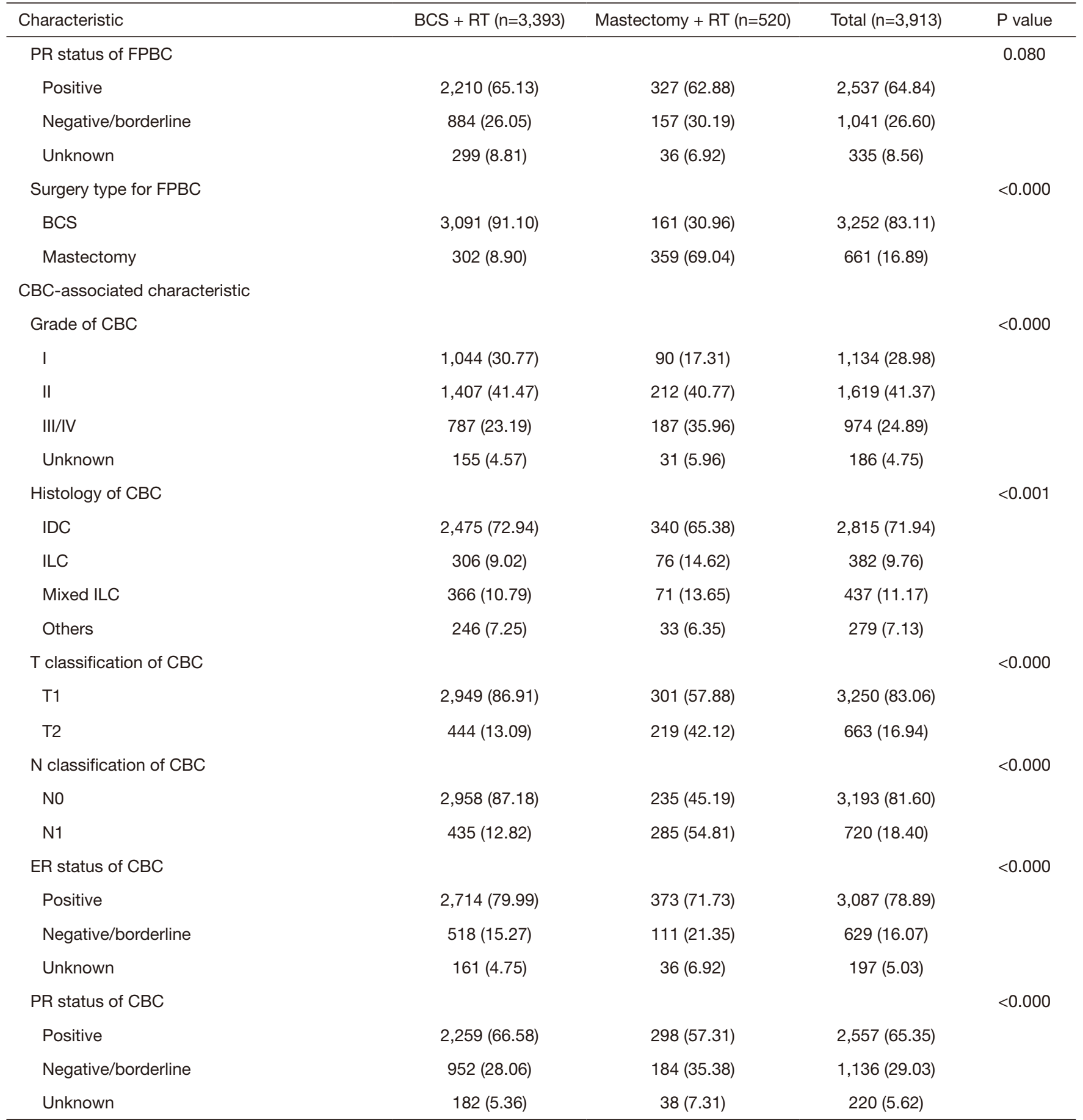

Data are shown as number (percentage). FPBC, first primary breast cancer; CBC, contralateral breast cancer; BCS, breast-conserving surgery; RT, radiotherapy; CoL, cost-of-living; IDC, infiltrating ductal carcinoma; ILC, infiltrating lobular carcinoma; ER, estrogen receptor; $\mathrm{PR}$, progesterone receptor. 


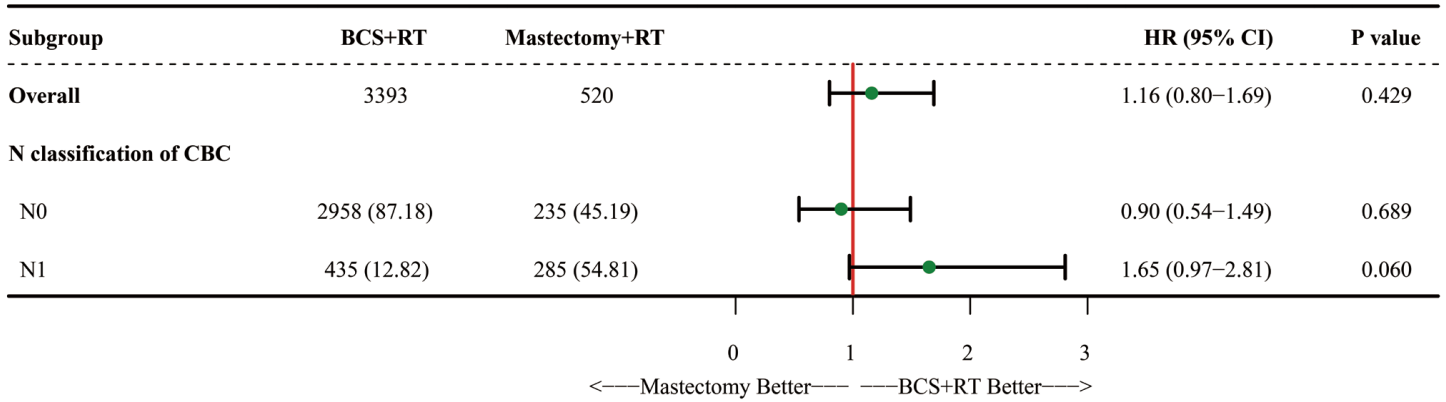

Figure 5 Multivariable analysis for BCSS as compared between BCS plus RT and mastectomy plus RT in early-stage CBC patients. Adjusted, if not be stratified, for age at CBC diagnosis, time interval, stage of FPBC, $\mathrm{T}$ and $\mathrm{N}$ classification of CBC, histology and hormone receptors status of both cancers, and surgery type for FPBC. BCSS, breast cancer-specific survival; HR, hazard ratio; CI, confidence interval; FPBC, first primary breast cancer; CBC, contralateral breast cancer; BCS, breast-conserving therapy; RT, radiotherapy.

increased probability of BRCA1/2 mutation $(25,26)$. The National Comprehensive Cancer Network guidelines state that such genetic predisposition might be a contraindication for BCS due to relatively high local recurrence rates (27). However, accumulated evidence has demonstrated that BCS plus radiotherapy did not impair the overall survival and metastasis-free survival of UBC patients with BRCA1/2 mutation (28-34); among these patients, the local recurrence post-BCS mainly occurred in the contralateral breast and the risk of ipsilateral breast recurrence did not differ from non-carriers $(28,30,32,34)$. This may be due to more radiosensitivity for BRCA1/2 mutation carriers, which has been supported by animal models (35) and clinical studies $(36,37)$. Fourque et al. (36) found that a higher complete or major response rate could be achieved in BRCA1/2 mutation carriers versus non-carriers after preoperative radiotherapy. A phase II non-randomized study (37) with a median 58-month follow-up was conducted to evaluate prophylactic contralateral breast irradiation for preventing CBC among UBC patients with BRCA1/2 mutation; prophylactic irradiation yielded an $80 \%$ reduction of CBC and delayed the onset time (32 vs. 92 months). Moreover, no evidence showed that radiation exposure increased toxicity or other primary cancer events in BRCA1/2 mutation carriers $(30,34,37)$.

Based on the above results, under the premise that cancer on the first involved breast had been given standardized treatment, the risk of local recurrence post-BCS among CBC patients with BRCA1/2 mutation would not be likely to be much higher compared with non-carriers. BCS plus radiotherapy may remain an adequate option for early-stage CBC patients with BRCA1/2 mutation. In our study, BCS plus radiotherapy did not impair BCSS outcomes of young CBC patients, among whom there was a higher proportion of BRCA1/2 mutation carriers (38). Of course, since genetic factors and information about local recurrence are not available from the SEER database, future prospective studies with long-term follow-up are needed.

Based on the time interval between FPBC and CBC diagnosis, CBC can be divided into SCBC and MCBC. In our study, we used 3 months ( 0.25 years) as the cut-off date to define SCBC and MCBC because the incidence of CBC peaks within 2 months of FPBC diagnosis (39). The prognosis comparison between SCBC and MCBC is different with the time interval. Consistent with previous studies (40-42), our study showed that a short time interval is a strong predictor of poor prognosis for MCBC and the survival of patients with MCBC improved with a prolonged time interval. Previously proposed biological properties of bilateral breast cancer may explain the differences in survival seen over time. SCBC can be regarded as a multifocal malignant disease (39), and late MCBC might be analogous to sporadic UBC, while early MCBC may indicate a therapyresistant phenotype $(40,42)$. It is worth noting that in our early-stage CBC cohort, positive-ER status, either in FPBC or $\mathrm{CBC}$, was not associated with a survival benefit, which also indicated a therapy-resistant phenotype, especially endocrine therapy resistance, in CBC patients.

Our present study showed that early-stage CBC patients undergoing BCS plus radiotherapy had similar BCSS outcomes compared with those undergoing mastectomy across subgroups with different time intervals $(<0.25$, $0.25-4,5-9, \geq 10$ years). The prognosis of these different subgroups of $\mathrm{CBC}$ patients may be determined by different 
biological behaviors and cannot be improved by expanding the extent of surgery.

For UBC patients, post-operation radiotherapy is a standard component of BCS but not that of mastectomy. Among UBC patients with small tumor size and negative lymph node status (T1-2N0M0), post-mastectomy radiotherapy is considered unnecessary (27). However, for T1-2N1M0 UBC patients, the role of post-mastectomy radiotherapy remains controversial. The Early Breast Cancer Trialists Collaborative Group (43) concluded that post-mastectomy radiotherapy reduced 20 -year breast cancer-associated mortality by $20 \%$ in UBC patients with 1-3 positive nodes (N1). However, modern enhanced chemotherapy and endocrine therapy have improved the local and distant control; hence, the need for post-mastectomy radiotherapy may be potentially obviated in these UBC patients $(44,45)$. Lan et al. directly compared survival outcomes between BCS plus radiotherapy and mastectomy plus radiotherapy in 196 pairs of UBC patients with T12N1M0 UBC using the PS matching method, showing BCS plus radiotherapy was associated with better distant metastasis-free survival, disease-free survival, and BCSS (46).

Little is known about the impact of post-mastectomy radiotherapy on $\mathrm{CBC}$. As radiotherapy-related information tends to be underreported in the SEER database (11), outcomes associated with mastectomy with and without radiotherapy are not directly comparable; thus, we separately compared survival outcomes between BCS plus radiotherapy and mastectomy plus radiotherapy in our early-stage CBC cohort. Results showed mastectomy plus radiotherapy did not confer a BCSS advantage over BCS plus radiotherapy in early-stage CBC patients regardless of lymph node status.

This study has some other limitations. The data on chemotherapy were also underreported, and the data on endocrine or target therapy were not available in the SEER database; however, the indications for these therapies are unrelated to the surgery type, and it is impossible for women receiving mastectomy to comply less with the recommended treatment than those receiving BCS. SEER does not report other detailed pathologic information, such as lymphovascular invasion, extracapsular invasion, or the presence of multifocal tumors that may have biased the results; however, these factors would not be expected to have a large impact, as Hwang et al. (47) and Agarwal et al. (48) have suggested. Patients' comorbidities are also not available in the SEER database, which may affect patients' choice and overall survival; thus, we used Fine and Gray's competing risks regression model to assess BCSS after eliminating death due to non-breast cancer causes, thus evaluating real treatment effects more reliably. Finally, we cannot obtain information about locoregional recurrence, thus precluding any meaningful discussions about the impact of BCS plus radiotherapy and mastectomy on disease-free survival in the study groups.

In conclusion, BCS plus radiotherapy did not significantly influence BCSS outcome in patients with early-stage CBC. The use of bilateral mastectomy and mastectomy plus radiotherapy did not confer a survival advantage over BCS plus radiotherapy in these patients. Future prospective studies are necessary to expand on these results.

\section{Acknowledgments}

Funding: This paper was supported by the National Natural Science Foundation of China (Grant Nos. 81773554 and 81972484), the National Natural Science Foundation of China Grant for Young Scientists (Grant Nos. 81302512).

\section{Footnote}

Reporting Checklist: The authors have completed the STROBE reporting checklist. Available at https://dx.doi. org/10.21037/gs-21-413

Conflicts of Interest: All authors have completed the ICMJE uniform disclosure form (available at https://dx.doi. org/10.21037/gs-21-413). The authors have no conflicts of interest to declare.

Ethical Statement: The authors are accountable for all aspects of the work in ensuring that questions related to the accuracy or integrity of any part of the work are appropriately investigated and resolved. The study was conducted in accordance with the Declaration of Helsinki (as revised in 2013). Informed consent or ethical approval was not required since SEER database only contain deidentified data and is available to the public.

Open Access Statement: This is an Open Access article distributed in accordance with the Creative Commons Attribution-NonCommercial-NoDerivs 4.0 International License (CC BY-NC-ND 4.0), which permits the noncommercial replication and distribution of the article with the strict proviso that no changes or edits are made and the 
original work is properly cited (including links to both the formal publication through the relevant DOI and the license). See: https://creativecommons.org/licenses/by-nc-nd/4.0/.

\section{References}

1. Siegel RL, Miller KD, Jemal A. Cancer statistics, 2020. CA Cancer J Clin 2020;70:7-30.

2. Miller KD, Nogueira L, Mariotto AB, et al. Cancer treatment and survivorship statistics, 2019. CA Cancer J Clin 2019;69:363-85.

3. Narod SA. Bilateral breast cancers. Nat Rev Clin Oncol 2014;11:157-66

4. Sakai T, Ozkurt E, DeSantis S, et al. National trends of synchronous bilateral breast cancer incidence in the United States. Breast Cancer Res Treat 2019;178:161-7.

5. NIH Consensus Development Conference statement on the treatment of early-stage breast cancer. Oncology (Williston Park) 1991;5:120-4.

6. Arriagada R, Lê MG, Rochard F, et al. Conservative treatment versus mastectomy in early breast cancer: patterns of failure with 15 years of follow-up data. Institut GustaveRoussy Breast Cancer Group. J Clin Oncol 1996;14:1558-64.

7. Clarke M, Collins R, Darby S, et al. Effects of radiotherapy and of differences in the extent of surgery for early breast cancer on local recurrence and 15-year survival: an overview of the randomised trials. Lancet 2005;366:2087-106.

8. Fisher B, Anderson S, Bryant J, et al. Twenty-year follow-up of a randomized trial comparing total mastectomy, lumpectomy, and lumpectomy plus irradiation for the treatment of invasive breast cancer. N Engl J Med 2002;347:1233-41.

9. Veronesi U, Cascinelli N, Mariani L, et al. Twentyyear follow-up of a randomized study comparing breastconserving surgery with radical mastectomy for early breast cancer. N Engl J Med 2002;347:1227-32.

10. Fine JP, Gray RJ. A proportional hazards model for the subdistribution of a competing risk. J Am Stat Ass 1999;94:496-509.

11. Noone AM, Lund JL, Mariotto A, et al. Comparison of SEER Treatment Data With Medicare Claims. Med Care 2016;54:e55-64.

12. Janschek E, Kandioler-Eckersberger D, Ludwig C, et al. Contralateral breast cancer: molecular differentiation between metastasis and second primary cancer. Breast Cancer Res Treat 2001;67:1-8

13. Fung MC, Schultz DJ, Solin LJ. Early-stage bilateral breast cancer treated with breast-conserving surgery and definitive irradiation: the University of Pennsylvania experience. Int J Radiat Oncol Biol Phys 1997;38:959-67.

14. Gollamudi SV, Gelman RS, Peiro G, et al. Breastconserving therapy for stage I-II synchronous bilateral breast carcinoma. Cancer 1997;79:1362-9.

15. Lee MM, Heimann R, Powers C, et al. Efficacy of Breast Conservation Therapy in Early Stage Bilateral Breast Cancer. Breast J 1999;5:36-41.

16. Yamauchi C, Mitsumori M, Nagata Y, et al. Bilateral breast-conserving therapy for bilateral breast cancer: results and consideration of radiation technique. Breast Cancer 2005;12:135-9.

17. O'Brien JA, Ho A, Wright GP, et al. Breast-Conserving Surgery in Bilateral Breast Cancer. Ann Surg Oncol 2015;22:3389-96.

18. de la Rochefordiere A, Asselain B, Scholl S, et al. Simultaneous bilateral breast carcinomas: a retrospective review of 149 cases. Int J Radiat Oncol Biol Phys 1994;30:35-41.

19. Chen JJ, Huang NS, Xue JY, et al. Surgical management for early-stage bilateral breast cancer patients in China. PLoS One 2015;10:e0122692.

20. Adkisson CD, Bagaria SP, Parker AS, et al. Which eligible breast conservation patients choose mastectomy in the setting of newly diagnosed breast cancer? Ann Surg Oncol 2012;19:1129-36.

21. Wong SM, Freedman RA, Sagara Y, et al. Growing Use of Contralateral Prophylactic Mastectomy Despite no Improvement in Long-term Survival for Invasive Breast Cancer. Ann Surg 2017;265:581-9.

22. Kurian AW, Lichtensztajn DY, Keegan TH, et al. Use of and mortality after bilateral mastectomy compared with other surgical treatments for breast cancer in California, 1998-2011. JAMA 2014;312:902-14.

23. Anderson C, Islam JY, Elizabeth Hodgson M, et al. Long-Term Satisfaction and Body Image After Contralateral Prophylactic Mastectomy. Ann Surg Oncol 2017;24:1499-506.

24. Rosenberg SM, Dominici LS, Gelber S, et al. Association of Breast Cancer Surgery With Quality of Life and Psychosocial Well-being in Young Breast Cancer Survivors. JAMA Surg 2020;155:1035-42.

25. Shattuck-Eidens D, Oliphant A, McClure M, et al. BRCA1 sequence analysis in women at high risk for susceptibility mutations. Risk factor analysis and implications for genetic testing. JAMA 1997;278:1242-50.

26. Ligtenberg MJ, Hogervorst FB, Willems HW, et al. Characteristics of small breast and/or ovarian cancer families with germline mutations in BRCA1 and BRCA2. 
Br J Cancer 1999;79:1475-8.

27. National Comprehensive Cancer Network (NCCN). Clinical practices guidelines in oncology, Breast Cancer (Version 4. 2021). Available online: http://www.nccn.org/ patients. Accessed 28 April 2021.

28. Ye F, Huang L, Lang G, et al. Outcomes and risk of subsequent breast events in breast-conserving surgery patients with BRCA1 and BRCA2 mutation. Cancer Med 2020;9:1903-10.

29. van den Broek AJ, Schmidt MK, van 't Veer LJ, et al. Prognostic Impact of Breast-Conserving Therapy Versus Mastectomy of BRCA1/2 Mutation Carriers Compared With Noncarriers in a Consecutive Series of Young Breast Cancer Patients. Ann Surg 2019;270:364-72.

30. Vallard A, Magné N, Guy JB, et al. Is breast-conserving therapy adequate in BRCA 1/2 mutation carriers? The radiation oncologist's point of view. Br J Radiol 2019;92:20170657.

31. Pierce LJ, Phillips KA, Griffith KA, et al. Local therapy in BRCA1 and BRCA2 mutation carriers with operable breast cancer: comparison of breast conservation and mastectomy. Breast Cancer Res Treat 2010;121:389-98.

32. Kirova YM, Savignoni A, Sigal-Zafrani B, et al. Is the breastconserving treatment with radiotherapy appropriate in BRCA1/2 mutation carriers? Long-term results and review of the literature. Breast Cancer Res Treat 2010;120:119-26.

33. Huang X, Cai XY, Liu JQ, et al. Breast-conserving therapy is safe both within BRCA1/2 mutation carriers and noncarriers with breast cancer in the Chinese population. Gland Surg 2020;9:775-87.

34. Tung NM, Boughey JC, Pierce LJ, et al. Management of Hereditary Breast Cancer: American Society of Clinical Oncology, American Society for Radiation Oncology, and Society of Surgical Oncology Guideline. J Clin Oncol 2020;38:2080-106.

35. Shuryak I, Smilenov LB, Kleiman NJ, et al. Potential reduction of contralateral second breast-cancer risks by prophylactic mammary irradiation: validation in a breastcancer-prone mouse model. PLoS One 2013;8:e85795.

36. Fourquet A, Stoppa-Lyonnet D, Kirova YM, et al. Familial breast cancer: clinical response to induction chemotherapy or radiotherapy related to BRCA1/2 mutations status. Am J Clin Oncol 2009;32:127-31.

37. Evron E, Ben-David AM, Goldberg H, et al. Prophylactic irradiation to the contralateral breast for BRCA mutation carriers with early-stage breast cancer. Ann Oncol 2019;30:412-7.

38. Steinmann D, Bremer M, Rades D, et al. Mutations of the
BRCA1 and BRCA2 genes in patients with bilateral breast cancer. Br J Cancer 2001;85:850-8.

39. Hartman M, Czene K, Reilly M, et al. Genetic implications of bilateral breast cancer: a population based cohort study. Lancet Oncol 2005;6:377-82.

40. Hartman M, Czene K, Reilly M, et al. Incidence and prognosis of synchronous and metachronous bilateral breast cancer. J Clin Oncol 2007;25:4210-6.

41. Langballe R, Frederiksen K, Jensen MB, et al. Mortality after contralateral breast cancer in Denmark. Breast Cancer Res Treat 2018;171:489-99.

42. Alkner S, Bendahl PO, Fernö M, et al. Prediction of outcome after diagnosis of metachronous contralateral breast cancer. BMC Cancer 2011;11:114.

43. EBCTCG (Early Breast Cancer Trialists' Collaborative Group); McGale P, Taylor C, et al. Effect of radiotherapy after mastectomy and axillary surgery on 10-year recurrence and 20-year breast cancer mortality: metaanalysis of individual patient data for 8135 women in 22 randomised trials. Lancet 2014;383:2127-35.

44. Kim YJ, Park W, Ha B, et al. Postmastectomy Radiotherapy in Patients with pT1-2N1 Breast Cancer Treated with Taxane-Based Chemotherapy: A Retrospective Multicenter Analysis (KROG 1418). Cancer Res Treat 2017;49:927-36.

45. Zeidan YH, Habib JG, Ameye L, et al. Postmastectomy Radiation Therapy in Women with T1-T2 Tumors and 1 to 3 Positive Lymph Nodes: Analysis of the Breast International Group 02-98 Trial. Int J Radiat Oncol Biol Phys 2018;101:316-24.

46. Lan XW, Wen G, He Z, et al. Comparison of long-term results between radiotherapy after breast-conserving surgery and postmastectomy radiotherapy in stage T1-2N1M0 breast cancer. Cancer Manag Res 2019;11:6477-87.

47. Hwang ES, Lichtensztajn DY, Gomez SL, et al. Survival after lumpectomy and mastectomy for early stage invasive breast cancer: the effect of age and hormone receptor status. Cancer 2013;119:1402-11.

48. Agarwal S, Pappas L, Neumayer L, et al. Effect of breast conservation therapy vs mastectomy on diseasespecific survival for early-stage breast cancer. JAMA Surg 2014;149:267-74.

Cite this article as: Qian C, Liang Y, Yang M, Bao SN, Bai JL, Yin YM, Yu H. Effect of breast-conserving surgery plus radiotherapy versus mastectomy on breast cancer-specific survival for early-stage contralateral breast cancer. Gland Surg 2021;10(10):2978-2996. doi: 10.21037/gs-21-413 
Supplementary

Table S1 Univariable analysis for BCSS in early-stage CBC patients

\begin{tabular}{lll}
\hline \multirow{2}{*}{ Characteristic } & \multicolumn{2}{c}{ BCSS } \\
\cline { 2 - 3 } & HR $(95 \% \mathrm{Cl})$ & P value \\
\hline
\end{tabular}

Demographic-associated characteristic

Race

$\begin{array}{lcc}\text { White } & \text { Reference } & \\ \text { Black } & 1.62(1.35-1.95) & <0.000 \\ \text { Others } & 0.87(0.69-1.11) & 0.261\end{array}$

CoL index of state of residence

$$
\begin{aligned}
& \leq 1,000 \\
& >1,000 \\
&
\end{aligned}
$$

Age at $\mathrm{CBC}$ diagnosis (years)

$\begin{array}{lc}\leq 50 & \text { Reference } \\ 51-60 & 0.80(0.67-1.95) \\ >60 & 0.80(0.68-0.92)\end{array}$

Interval time (months)

$\begin{array}{lcc}0-2 & \text { Reference } & \\ 3-59 & 1.40(1.22-1.60) & <0.001 \\ 60-119 & 1.03(0.86-1.22) & 0.760 \\ \geq 120 & 0.55(0.37-0.80) & 0.002\end{array}$

FPBC-associated characteristic

Grade of FPBC

।

II

III/IV

Reference

Histology of FPBC

IDC

ILC

Mixed ILC

1.33 (1.10-1.61)

0.004

Others

0.90 (0.74-1.09)

$0.95(0.78-1.17)$

0.291

0.657

Stage of FPBC

Stage I

Reference

Stage II

2.28 (1.97-2.65)

$<0.000$

Stage III

5.92 (5.04-6.96)

$<0.000$

ER status of FPBC

Positive

Reference

Negative/borderline

1.59 (1.38-1.83)
Table S1 (continued)

\begin{tabular}{lcc}
\hline \multirow{2}{*}{ Characteristic } & \multicolumn{2}{c}{ BCSS } \\
\cline { 2 - 3 } & HR $(95 \% \mathrm{Cl})$ & P value \\
\hline PR status of FPBC & Reference & \\
Positive & $1.49(1.31-1.70)$ & $<0.000$ \\
Negative/borderline & & \\
Surgery type for FPBC & Reference & \\
BCS & $1.41(1.24-1.59)$ & $<0.000$ \\
Mastectomy &
\end{tabular}

CBC-associated characteristic

Grade of CBC

I

Reference

II

III/IV

1.54 (1.24-1.89)

$<0.000$

1.58 (1.24-2.03)

$<0.000$

Histology of CBC

IDC

Reference

ILC

Mixed ILC

$1.04(0.86-1.27)$

0.659

Others

0.89 (0.74-1.08)

0.231

$0.97(0.77-1.22)$

0.797

T classification of $\mathrm{CBC}$

T1

Reference

$\mathrm{T} 2$

$2.40(2.11-2.73)$

$<0.000$

$\mathrm{N}$ classification of $\mathrm{CBC}$

NO

Reference

N1

$2.35(2.06-2.67)$

$<0.000$

ER status of CBC

Positive

Negative/Borderline

Reference

$1.82(1.58-2.11)$

PR status of $\mathrm{CBC}$

Positive

Reference

Negative/borderline

$1.76(1.54-2.00)$

$<0.000$

Surgery type for FPBC

$\mathrm{BCS}+\mathrm{RT}$

Reference

Mastectomy

$1.58(1.38-1.81)$

$<0.000$

BCSS, breast cancer-specific survival; HR, hazard ratio; $\mathrm{Cl}$, confidence interval; FPBC, first primary breast cancer; CBC, contralateral breast cancer; BCS, breast-conserving surgery; $\mathrm{RT}$, radiotherapy; CoL, cost-of-living; IDC, infiltrating ductal carcinoma; ILC, infiltrating lobular carcinoma; ER, estrogen receptor; PR, progesterone receptor. 
Table S2 Baseline characteristics between BCS plus RT and mastectomy in early-stage CBC patients after PS matching

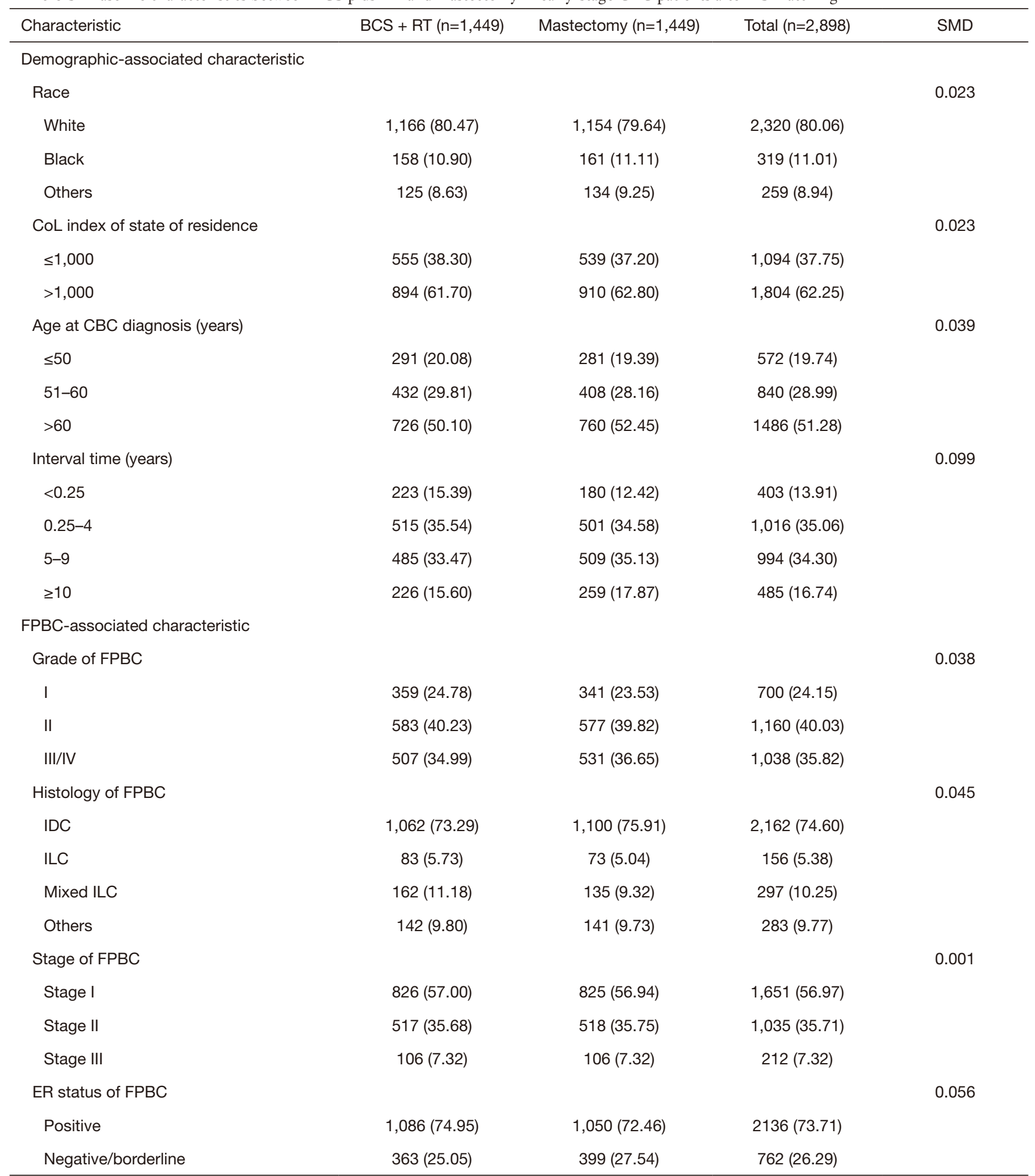

Table S2 (continued) 
Table S2 (continued)

\begin{tabular}{|c|c|c|c|c|}
\hline Characteristic & $B C S+R T(n=1,449)$ & Mastectomy $(n=1,449)$ & Total $(n=2,898)$ & SMD \\
\hline Positive & $958(66.11)$ & $914(63.08)$ & $1,872(64.60)$ & \\
\hline Negative/borderline & $475(32.78)$ & $510(35.20)$ & 985 (33.99) & \\
\hline Unknown & $16(1.10)$ & $25(1.73)$ & $41(1.41)$ & \\
\hline BCT & $1,204(83.09)$ & 1,198 (82.68) & 2,402 (82.88) & \\
\hline Mastectomy & $245(16.91)$ & $251(17.32)$ & $496(17.12)$ & \\
\hline \multicolumn{5}{|c|}{ CBC-associated characteristic } \\
\hline \multicolumn{5}{|l|}{ Grade of CBC } \\
\hline III/IV & $505(34.85)$ & $509(35.13)$ & $1014(34.99)$ & \\
\hline Histology of CBC & & & & 0.027 \\
\hline IDC & $1,093(75.43)$ & $1,082(74.67)$ & $2,175(75.05)$ & \\
\hline ILC & $129(8.90)$ & $126(8.70)$ & $255(8.80)$ & \\
\hline Mixed ILC & $156(10.77)$ & $161(11.11)$ & $317(10.94)$ & \\
\hline Others & $71(4.90)$ & $80(5.52)$ & $151(5.21)$ & \\
\hline T classification of $\mathrm{CBC}$ & & & & 0.002 \\
\hline $\mathrm{T} 1$ & $1,135(78.33)$ & $1,134(78.26)$ & $2,269(78.30)$ & \\
\hline Positive & $1,089(75.16)$ & $1,091(75.29)$ & $2,180(75.22)$ & \\
\hline Negative/borderline & $360(24.84)$ & $358(24.71)$ & $718(24.78)$ & \\
\hline PR status of $\mathrm{CBC}$ & & & & 0.066 \\
\hline Positive & $908(62.66)$ & $858(59.21)$ & $1,766(60.94)$ & \\
\hline Negative/borderline & $533(36.78)$ & $577(39.82)$ & $1,110(38.30)$ & \\
\hline Unknown & $8(0.55)$ & $14(0.97)$ & $22(0.76)$ & \\
\hline
\end{tabular}

PS, propensity score; SMD, standardized mean difference; FPBC, first primary breast cancer; CBC, contralateral breast cancer; BCS, breast-conserving surgery; RT, radiotherapy; CoL, cost-of-living; IDC, infiltrating ductal carcinoma; ILC, infiltrating lobular carcinoma; ER, estrogen receptor; PR, progesterone receptor. 


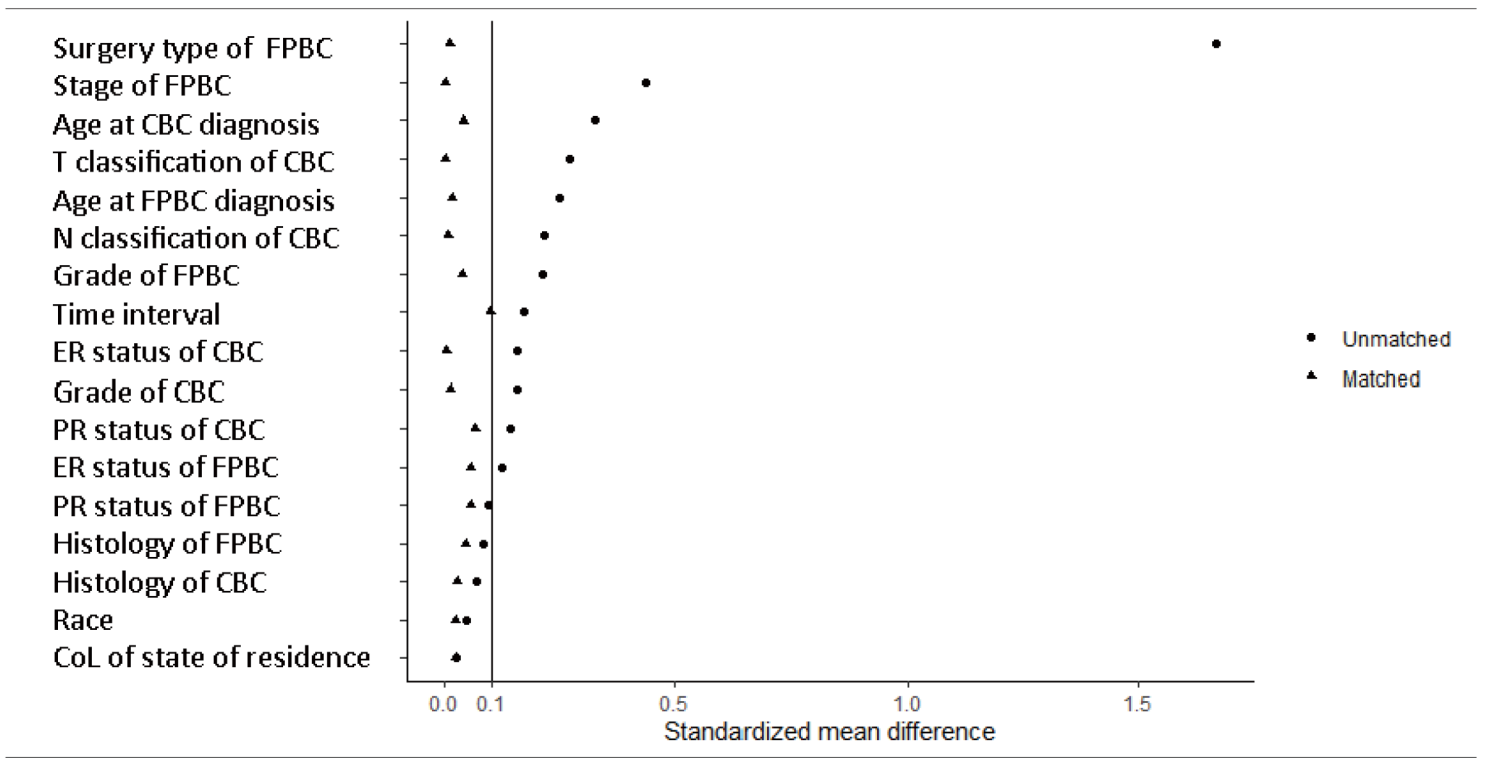

Figure S1 Absolute standardized mean differences for baseline covariates between BCS plus RT and mastectomy in the unmatched and the matched sample. FPBC, first primary breast cancer; CBC, contralateral breast cancer; BCS, breast-conserving surgery; RT, radiotherapy; CoL, cost-of-living; ER, estrogen receptor; PR, progesterone receptor. 
Table S3 Baseline characteristics between BCS plus RT and mastectomy plus RT in early-stage CBC patients after PS matching

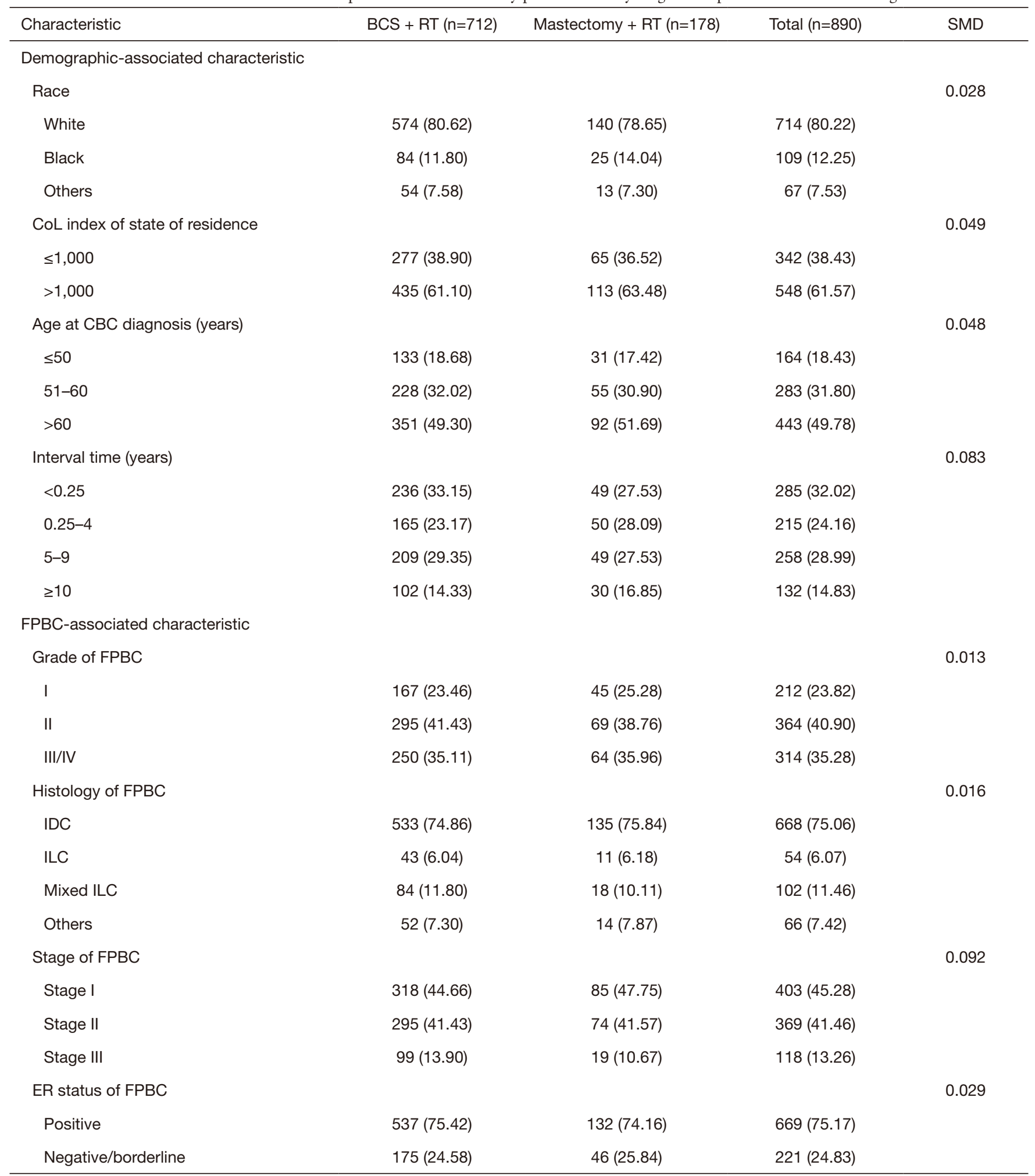

Table S3 (continued) 
Table S3 (continued)

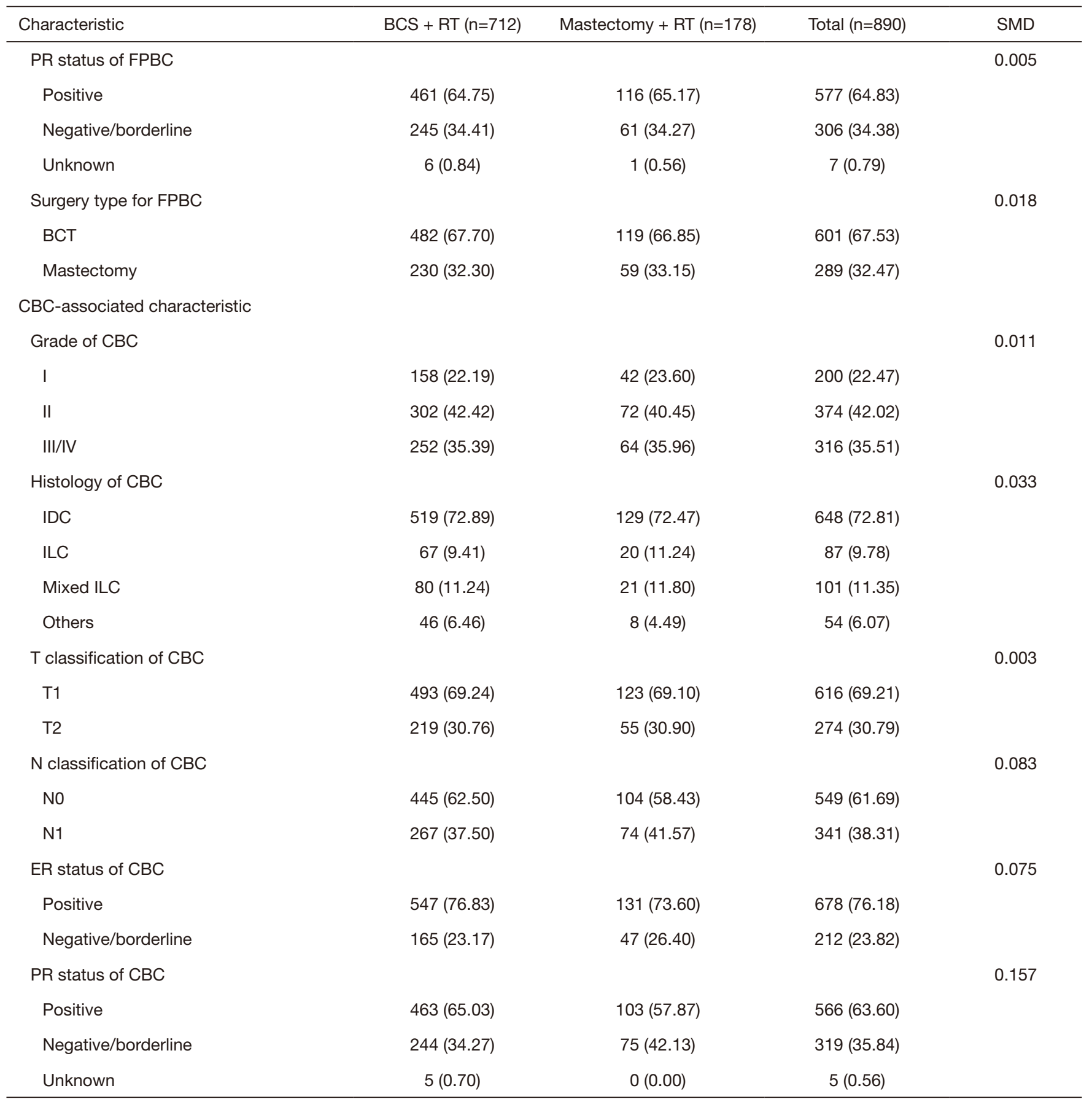

PS, propensity score; SMD, standardized mean difference; BCS, breast-conserving surgery; RT, radiotherapy; FPBC, first primary breast cancer; CBC, contralateral breast cancer; CoL, cost-of-living; IDC, infiltrating ductal carcinoma; ILC, infiltrating lobular carcinoma; ER, estrogen receptor; PR, progesterone receptor. 


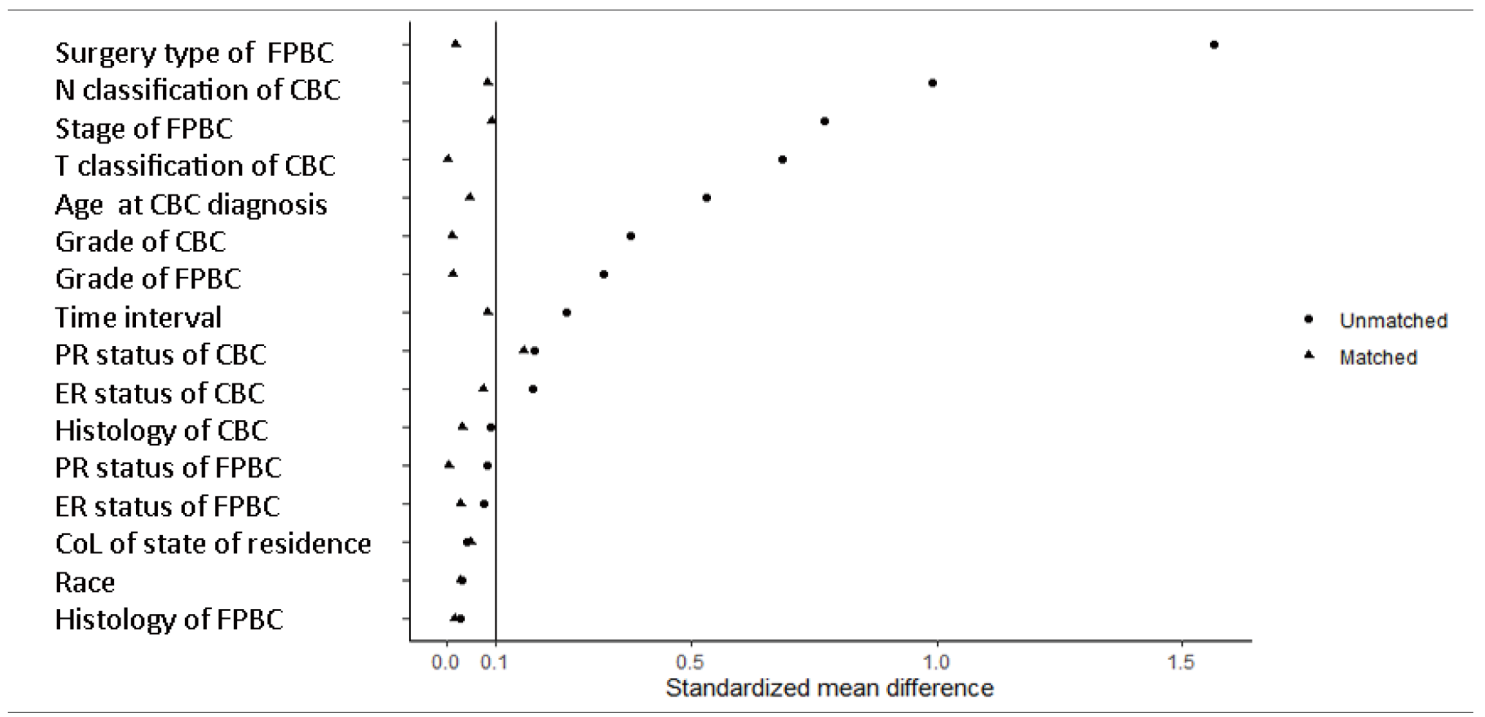

Figure S2 Absolute standardized mean differences for baseline covariates between BCS plus RT and mastectomy plus RT in the unmatched and the matched sample. FPBC, first primary breast cancer; CBC, contralateral breast cancer; BCS, breast-conserving surgery; RT, radiotherapy; CoL, cost-of-living; ER, estrogen receptor; PR, progesterone receptor.

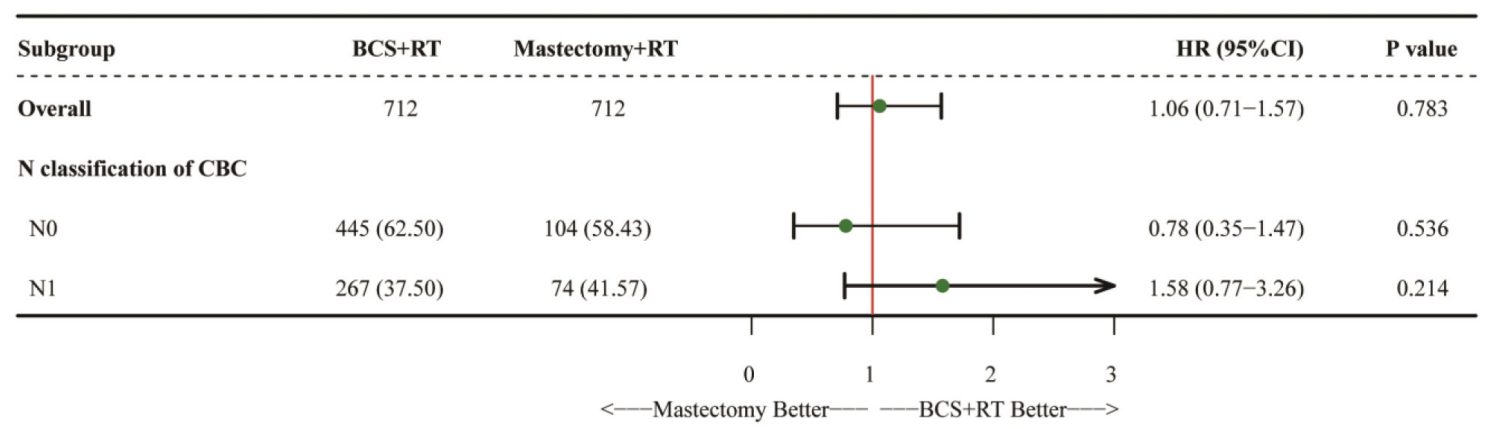

Figure S3 Multivariable analysis for BCSS as compared between BCS plus RT and mastectomy plus RT in early-stage CBC patients after PS matching. Adjusted, if not be stratified, for age at CBC diagnosis, time interval, stage of FPBC, T and N classification of CBC, histology and hormone receptors status of both cancers, and surgery type for FPBC. BCSS, breast cancer-specific survival; HR, hazard ratio; CI, confidence interval; FPBC, first primary breast cancer; CBC, contralateral breast cancer; BCS, breast-conserving therapy; RT, radiotherapy. 